\section{Miguel Ponce Cuéllar}

Centro Superior de Estudios Teológicos de Mérida-Badajoz

Pontifica Academia Mariana Internacional

mponcec7@gmail.com

DOI: http://dx.doi.org/10.12775/BPTh.2016.022

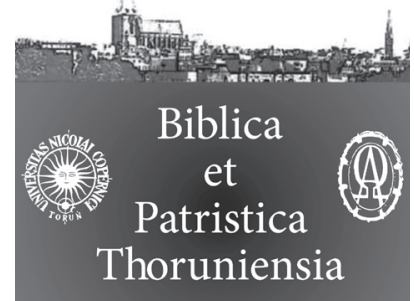

9 (2016) 3: 59-93

ISSN (print) 1689-5150

ISSN (online) 2450-7059

\title{
Actualidad del pensamiento ecclesiológico de Santo Tomás
}

\section{The Topicality of Ecclesiological Thought of St. Thomas}

\section{Aktualność myśli eklezjologicznej św. Tomasza z Akwinu}

Resumen. En los Comentarios de san Pablo, santo Tomás ofrece una visión de la Iglesia en cuanto "comunión con el Padre, en el Hijo y por el Espíritu Santo", lo que deja claro que la Iglesia se construye como don, desde arriba, desde el Padre. La hondura de su pensamiento aparece no sólo en esta definición de su naturaleza sino también en el significado de la Humanidad de Cristo como exemplar de la Iglesia. Estas dos afirmaciones son la clave para entender el misterio eclesial y su realización en los diversos estadios como verdadero misterio, que encuentra su plena realización en el estadio final, la "vera Ecclesia”. Fuente de unidad de esta Iglesia es el Espíritu Santo, dador tanto de las gracias "gratum faciens" como de las gracias "gratis datas", pero en definitiva es su propia presencia la que estructura en unidad a la Iglesia entera. A la pregunta sobre por qué no escribió santo Tomás un tratado responde el autor del artículo con Le Guillou, entre otros, porque la Iglesia es el espacio donde se vive todo el misterio cristiano y habría que repetir toda su teología

Nei commenti alle Lettere di san Paolo, san Tommaso d'Aquino offre una visione della Chiesa in quanto "comunione con il Padre, nel Figlio e per lo Spirito Santo", per cui manifesta che la Chiesa si costruisce come dono che viene dall'alto e, in concreto, dal Padre. La densità del pensiero del Dottore Angelico si vede nella definizione della natura del mistero ecclesiale, e si rende palese anche nel significato dell'Umanità di Cristo, che egli considera esemplare della Chiesa. Queste due affermazioni sono la chiave per cogliere il mistero della Chiesa e percepire la sua realizzazione nele diverse fasi dell'economia della salvezza in quanto vero mistero. Tale mistero trova la sua piena realizzazione nello stato finale: la "vera Ecclesia". Lo Spirito Santo è la fonte di unità di questa Chiesa. Egli è chi dona le grazie "gratum faciens" e le grazie "gratis datas". Tuttavia, la causa che struttura e unisce tutta la Chiesa è la Sua stessa presenza in essa. L'Autore dell'articolo risponde alla domanda sull'assenza di un trattato De Ecclesia nell'opera di San Tommaso con idee di Le Guillou, tra altri autori: perché la Chiesa è lo spazio dove si vive tutto il mistero cristiano e, quindi, per fare un trattato De Ecclesia sarebbe necessario ripetere tutta la teologia del grande dottore domenicano. 


\begin{abstract}
In the Commentaries on the Letters of St. Paul, St. Thomas offers a vision of the Church concerning "communion with the Father, in the Son and by the Holy Spirit" which clarifies that the Church is built as a gift, from above, from the Father. The depth of his thought appears not only in this definition of her nature but also in signifying the Humanity of Christ as exemplary of the Church. These two affirmations are the key to understand the ecclesial mystery and its realisation at different stages as the true mystery which finds its full realisation at the final stage, the vera Ecclesia. The source of this unity of the Church is the Holy Spirit, the giver of both gratum faciens as well asgratis datas, but definitely it is His real presence, the one which structures the unity of the entire Church. In order to answer the question why St. Thomas did not write a treaty, the author of the article repeats after Le Guillou that, among other reasons, it was because the Church is the space where the entire Christian mystery is alive and all his theology should be repeated.
\end{abstract}

Streszczenie. W komentarzach do Listów św. Pawła św. Tomasz z Akwinu prezentuje wizję Kościoła jako „wspólnoty z Ojcem, w Synu, przez Ducha Świętego”, która rozjaśnia, że Kościół jest budowany jako dar z góry, dar od Ojca. Głębia myśli Akwinaty ukazuje się nie tylko w tej definicji natury Kościoła, lecz także w znaczeniu człowieczeństwa Chrystusa jako wzorca Kościoła. Te dwa stwierdzenia są kluczem dla zrozumienia eklezjalnej tajemnicy i jej realizacji w różnych stadiach jako prawdziwa tajemnica, która znajduje swoją pełną realizację w stadium końcowym, tj. vera Ecclesia. Źródłem tej jedności Kościoła jest Duch Święty, dawca łaski, zarówno gratum faciens, jak i gratis datas, jednak jego realna obecność konstruuje jedność całego Kościoła. W odpowiedzi na pytanie, dlaczego Tomasz z Akwinu nie napisał taktatu, autor artykułu powtarza za Le Guillou, że Kościół jest przestrzenią, gdzie cała chrześcijańska tajemnica jest przeżywana i cała jego teologia może być powtarzana.

Palabras claves: Iglesia; misterio; Humanidad de Cristo; sacramento; naturaleza; diversos estadios; verdadera Iglesia; comunión; gracia; hijos adoptivos; ministerio.

Keywords: Church; mistery; humanity of Christ; sacrament; naturality; community; different stages; vera Ecclesia; gift; adoptive son; ministry.

Słowa kluczowe: Kościół; tajemnica; człowieczeństwo Chrystusa; sakrament, naturalność; różne stadia; prawdziwy Kościół; wspólnota; łaska; syn adoptowany; posługa. 


\section{Prólogo}

$\mathrm{C}$ uando escribía la tesis doctoral sobre la naturaleza de la Iglesia en santo Tomás en las Cartas paulinas, allá por el año de 1975, me extrañó la frescura teológica de su pensamiento, bebido en las fuentes limpias de la Sagrada Escritura ${ }^{1}$. Entonces pude comprender que santo Tomas, leído directamente sin intermediarios que lo desvirtúen o tal vez lo fosilicen, seguía siendo profundamente actual, con esa actualidad que no cede al gusto del momento, sino que se adentra en las entrañas más profundas de la teología, para sorprendernos con un pensamiento vivo y rico, totalmente alejado del intelectualismo estéril, que a veces se le achaca ${ }^{2}$.

A la hora de preparar este artículo, me resultó extraño descubrir que desde los años ochenta apenas se ha vuelto a tratar de la eclesiología de santo Tomás. Es la impresión que me he llevado al hojear la bibliografía relativa a este tema ${ }^{3}$.

El estudio de la eclesiología del Angélico, cuya riqueza está entroncada con la más recia tradición patrística y escriturística, junto a otros factores de renovación, fue una de las razones que rompió las barreras de la eclesiología de defensa y condujo a la nueva visión, plasmada en la Constitución Lumen gentium del Vaticano II. No obstante, aunque muchas intuiciones tomistas han sido incorporados al Vaticano II, es cierto que la eclesiología del Angélico es incompleta desde el punto de vista de los parámetros modernos. Le falta un tratamiento adecuado de la infalibilidad papal, del pueblo de Dios, del ecumenismo y de la colegialidad episcopal, etc. No obstante su fuerte sentido sacramental, su visión de la participación en el sacerdocio de Cristo por medio del culto tomado en sentido amplio, su pneumatología y su visión de la gracia de Cristo Cabeza, contribuyen a ofrecernos la eclesiología a que antes hice alusión. Además, su pensamiento notablemente avanzado para su época, su implicación en todas las controversias del momento, su insaciable apetito de búsqueda de

1 M. Ponce Cuéllar, La naturaleza de la Iglesia, pp. 257-260.

2 Este trabajo ha sido realizado con la ayuda del Centro Español de Estudios Eclesiásticos anejo a la Iglesia Nacional Española de Santiago y Montserrat en Roma en el marco de los proyectos de investigación del curso 2014-2015.

3 El artículo de I. Jericó Bermejo, Anotaciones sobre la Iglesia; J.-P. Torrell, Saint Thomas d'Aquin. Nada dice del tema, R. Ingardia, Thomas Aquinas. International bibliography, pp. 1971990; S.-T. Bonino, Saint Thomas au XX siècle; S-T. Bonino (Coord), Thomistes o l'actualité; J.P. Torrel, Iniciación a Tomás de Aquino: ni en los textos ni en la bibliografía hay nada de la eclesiología de Santo Tomás. En la sección relativa a la bibliografía de Santo Tomás de Recherches de Sciences Religieusses, tampoco encontré nada. Poco descubrí en los tomos de Rassegna de Letteratura tomistica. A destacar "Societé" et "communion" chez saint Thomas d'Aquin, RTh, pp. 387-622; R.M. Schmitz, De nexu Christum; P. Roszak, Christus transformat se in Ecclesiam. 
textos e instrumentos teológicos nuevos y más precisos, lo alejan totalmente de una "acartonada eclesiología ad mentem S. Thomae". Pienso que la frescura de la eclesiología tomasina hay que buscarla en su profunda y viva lectura de la $\mathrm{Pa}-$ labra de Dios. De aquí la riqueza de su eclesiología en los comentarios a Pablo.

Pero sorprendentemente los grandes conocedores de Sto. Tomas en la materia eclesiológica -Grabmann ${ }^{4}$, Geiselmann ${ }^{5}$, Congar ${ }^{6}$, Kaepelli ${ }^{7}$, etc.- sólo tuvieron encuenta sus obras sistemáticas(fundamentalmente la Suma Teológica -q. 8 de la III Parte-, donde expone la gracia capital de Cristo), pero sin adentrarse en sus Comentarios a las Cartas de S. Pablo -rico arsenal que el propio Grabmann reconoce-, que permanecía prácticamente ignorado ${ }^{8}$. No es extraña esta riqueza, pues ya conocemos que la gran teología medieval encuentra su inspiración en la lectura directa y en la exposición de la Sagrada Escritura, y santo Tomás no es una excepción.

Precisamente limitar el campo de los escritos del Angélico sólo a la tercera parte de la Suma o a sus tardíos sermones sobre el Credo de los apóstoles (año $1273)^{9}$, dio lugar a sostener posturas totalmente contradictorias sobre su pensa-

4 Dice que Santo Tomás -en su Prólogo general a los Comentarios del Corpus paulinum encuentra en las cartas de San Pablo toda la enseñanza sobre la Iglesia expuesta orgánicamente: "En las cartas del Apóstol de las gentes... encuentra santo Tomás toda la enseñanza de la Iglesia orgánicamente considerada” (M. Grabmann, Die Lehre des heiligen Thomas, p. 5).

5 J. Geiselman, Christus und die Kirche.

6 J.-M.Y. Congar, L'idée de l'eglise.

7 Th.M. Kaepelli, Zur Lehre des hl. Thomas.

8 M. Arias Reyero, que consagró su tesis doctoral a su estudio, considera los comentarios como la parte menos original de la obra del Doctor Común (Thomas von Aquin als Exeget, p. 26). Afortunadamente en los últimos 50 años los seguidores de Santo Tomás se ha interesado cada vez más por estos escritos. Decía el Papa Pío XII en una alocución a los profesores y estudiantes del Angelicum, el 14 enero de 1958: "Sus comentarios (de santo Tomás) sobre los libros del Antiguo y del Nuevo Testamento, y en primer lugar sobre las cartas de San Pablo, se distinguen por una profundidad, delicadeza y discernimiento tan grandes, que pueden ser contados entre las obras teológicas mayores del Santo. Se estima que proveen precisamente a estas obras de un importante complemento bíblico" (AAS 50 [1958)]151-152). Cfr. L. Elders, Tomás de Aquino, comentador.

9 Este es el esquema que propone en estos sermones: La Iglesia es un cuerpo, cuya alma es el Espíritu Santo. Es una congregación con cuatro características. La Iglesia es una por tres causas: la unidad de la fe, de la esperanza y del amor, y es necesaria para la salvación. Es santa, por ser templo del Espíritu Santo, por la sangre de Cristo y la unción del Espíritu por la gracia. Además, por la inhabitación en ella de la Trinidad y la invocación del nombre del Señor. Es católica: existe a lo largo y ancho del mundo; consta de tres partes: la de la tierra, la del cielo y la del purgatorio. También lo es en cuanto que incluye a todos, hombres y mujeres, y porque se inició en los tiempos de Abel y durará hasta el fin del mundo. Tras la consumación de los tiempos, perdurará en el cielo. Es firme, ya que Cristo es su principal fundamento; su segundo fundamento son los apóstoles y su doctrina, y por eso se la llama apostólica. Pedro es la cabeza de la Iglesia, cuya firmeza 
miento eclesiológico. Y así, E. Mersch reduce la eclesiología de Santo Tomas a la gracia capital ${ }^{10}$; F. Malmberg la califica de insuficiente, porque cree ver en ella un concepto espiritual de cuerpo y una insistencia sobre el carácter provisional de la Iglesia ${ }^{11}$; para A. Mitterer el santo tiene una concepción ahistórica de la Iglesia, al afirmar que ésta comienza $a b \mathrm{Abel}^{12}$, y E. Benz le tacha de haber clericalizado e institucionalizado el Reino de Dios, confundiendo lo escatológico con su realización histórica ${ }^{13}$. G. Sabra, desde el campo protestante, piensa que no se integran en el pensamiento de santo Tomás el aspecto de la comunión de los fieles y el aspecto institucional ${ }^{14}$. Podríamos alargar la lista, pero es suficiente esta muestra para asentar que quien acude al Angélico, limitándose a determinados pasajes y olvidando otros -como los Comentarios bíblicos- o con el deseo de encontrar soluciones inmediatas a problemas actuales sin remontarse a los principios fundamentales e imponiendo su propia lógica, tergiversa claramente la doctrina del santo de Aquino. Es necesario para captar su verdadero pensamiento, no desperdiciar fuente alguna -los Comentarios a S. Pablo son insustituibles- y después reconstruir su pensamiento sobre la base de un minucioso análisis. Tal vez la razón de que los autores eligieran sus obras especulativas para el estudio de la Iglesia en el Angélico pueda hallarse en la dificultad de encontrar un camino, que desbroce su pensamiento en la multitud de afirmaciones dispersas a lo largo de todos sus comentarios a las Cartas paulinas.

Sin embargo, el propio Santo Tomás ofrece una clave para la lectura de estas cartas, pues según él no siguen un orden cronológico, sino estructural teológico ${ }^{15}$, lo que indica que en esos comentarios hay una verdadera sistematización ${ }^{16}$. Desde esta perspectiva crece la importancia de los Prólogos, tanto el

las persecuciones, los errores y el mal no podrán conmover; florece en la fe de Pedro y está libre de error.
10 E. Mersch, Le corps mystique du Christ.
11 F. Malmberg, Ein Leib.
12 A. Mitterer, Geheimnisvoller Leib Christi.
13 E. Benz, Joachim Studien III.
14 G. Sabra, Thomas Aquinas' vision of the Church, p. 30.

15 "Sed dicendum est quod epistola ad Corinthios prior est in tempore scripturae. Sed epistola ad Romanos praemittitur... tum quia etiam hoc exigit ordo doctrinae ut prius gratia consideretur in se quam ut in sacramento" (In Epist S, Pauli Expos Prol).

16 Lo que Leo Elders dice con relación al comentario a la Carta a los romanos, es válido para el resto de los comentarios: "El comentario de Santo Tomás es una obra maravillosa por su fidelidad a lo que escribe Pablo, por las explicaciones de frases a veces difíciles y por su familiaridad con la Biblia que le permite ilustrar lo que está escrito con numerosas citas bíblicas. Es un comentario doctrinal y a la vez espiritual, invitando al lector a adaptar su existencia cristiana a lo que el texto dice" (L. Elders, La actualidad de la carta, p. 454). 
general como los particulares, ya que todo el conjunto de las cartas responde, en su orden actual, a un claro y unificador pensamiento teológico. Interesa, entonces, descubrir cuál es la idea base que estructura el conjunto y cada carta en particular, puesto que además -según el Angélico- en cada carta San Pablo no desarrolla más que un único pensamiento ${ }^{17}$.

\section{Cuestiones introductorias}

\subsection{El estudio de los Prólogos a las Cartas paulinas}

El genio sintetizador de Santo Tomás brilla de manera especial en sus prólogos a las Cartas paulinas. En ellos el Aquinatense hace gala de su asombrosa capacidad de síntesis y de su genio sistematizador. Por eso se convierten en una referencia obligada. En el Prólogo general a las Cartas, la idea central, a la cual reduce toda la materia es la enseñanza sobre $\mathrm{Cristo}^{18}{ }^{18}$, que identifica con la doctrina de su gracia ${ }^{19}$, pero con una clara visión eclesial, estableciendo entonces una doble distinción. Considera primero a las personas que integran la Iglesia de acuerdo con la imagen del cuerpo natural ${ }^{20}$ : Cristo, los miembros principales (Prelados), y toda la Iglesia (Cuerpo Místico); en segundo lugar, mira a la gracia en sí, los medios de donación de esa gracia (sacramentos y ministros), y el efecto de unidad que produce en la Iglesia, unidad que perdura en la escatología.

La primera división tiene en cuenta la imagen del cuerpo, en el cual cada miembro realiza su función específica. Así, en primer lugar, la Cabeza, "de quien fluye la vida a todo el cuerpo"21; en un segundo momento, los miembros principales, que son los ministros de los sacramentos ${ }^{22}$, y, por último, todos los demás, que participando de la "gracia divina y de la comunión"23, forman con los ministros la "unidad de la Iglesia".

17 "Expositio est secundum Glossam. Sed tamen non est secundum intellectum Apostolicum, nec praecedentibus, nec sequentibus concordat. Nam ipse cum habeat unam materiam continuam de quq loquitur, non interponit aliam" (II Ad Cor 5, 1).

18 "quia tota haec est de doctrina Christi" (In Epist. S. Paul. Expos. Prol 10; Conf. Ad Gal 1,8).

19 "Est enim haec doctrina tota de gratia Christi" (In Epist. S. Pauli Expos. Prol).

20 Ad Heb Prol.

21 Ad Heb Prol.

22 I Ad Cor Prol.

23 Ad Heb 4,7. 
El esquema propuesto por Santo Tomás es claro. Todas las cartas de San Pablo tienen una orientación eclesiológica con una base cristológica, donde el elemento que se destaca es precisamente la gracia de Cristo ${ }^{24}$. Desde este punto de vista irá después estructurando cuantos elementos componen la Iglesia, de modo que cada uno de ellos -como se deduce del Prólogo general- ocupará un lugar propio según la relación que tenga con la gracia. Así la gracia en sí considerada, es el tema de la Carta a los Romanos; la gracia en cuanto comunicada por los sacramentos, 1 Corintios; en cuanto comunicada por los ministros de los sacramentos, 2 Corintios; en cuanto excluye los sacramentos (ritos) superfluos (de la Ley Antigua), Gálatas; en sus efectos en la institución de la Iglesia, Efesios; en la confirmación y el desarrollo de la comunidad, Filipenses; en el combate contra los errores, Colosenses; en cuanto nos ayuda en las dificultades y los combates presentes, 1 Tesalonicenses; en cuanto nos arma contra los sufrimientos futuros, 2 Tesalonicenses; en cuanto a la instrucción de quienes gobiernan al pueblo que recibió la gracia, 1 Timoteo; en cuanto muestra cómo los dirigentes de la comunidad sufren por el pueblo, 2 Timoteo; y cómo deben reprimir el mal, Tito; o cómo los maestros deben comportarse frente a sus súbditos, Filemón; en cuanto que la gracia de la Cabeza de la Iglesia "influye" en ella donando su gracia, Hebreos. Y como epígrafe sustentativo del contenido propio de cada carta, añade una frase de la Escritura.Veamos en esquema los aspectos desarrollados en cada una de las cartas.

\subsubsection{Cristo en la Carta a los Hebreos}

La carta a los Hebreos resalta la grandeza de Cristo, porque es el Hijo de Dios ${ }^{25}$ y el Verbo Revelador del Padre ${ }^{26}$. En cuanto Dios es "auctor", y en cuanto Hombre es "minister", porque administra los misterios (sacramentos) de la gracia en el presente y de la gloria en el futuro, ya que su Humanidad es "como un órgano de la divinidad" 27 . Como efecto de su sacrificio redentor "somos perfeccionados y unidos (coniungimur) a Dios" ${ }^{28}$, ya que por Él nos mereció la gracia, y para que el hombre se una a Dios, se requiere el auxilio de ésta. Por su

24 Ranft, después de presentar el esquema que Santo Tomás propone en el Prólogo general a los comentarios al Corpus paulinum, afirma que lo primordial en su sistema eclesiológico es la gracia: "El primado de santo Tomás con relación a su idea sistemática de la Iglesia es el pensamiento de la gracia" (J. Rantf, Die Stellung der Lehre, p. 74).

25 Ad Heb 1,1.

26 Ad Heb 1,1.

27 "sicut organum divinitatis" (Ad Heb 8,2).

28 Ad Heb 10,14. 
pasión consiguió para Él la exaltación ${ }^{29}$, y a nosotros “intra caelestia sancta nos introducit ad Patrem" ${ }^{30}$, como Pontífice Mediador que es. Al resucitar sube al cielo, "para prepararnos un camino... pues el cuerpo debe seguir a su Cabeza" 31 .

Los puntos más salientes de esta carta son el papel de la Humanidad de Cristo como "minister" sacerdotal de la gracia, y el aspecto de la unión a Dios, que ésta comporta. También, y de modo global, subrayamos la base cristológica, que el Angélico propone como fundamento de la eclesiología.

\subsubsection{La gracia "en sí" en el Comentario a la carta a los Romanos}

Recordemos que para el Aquinatense el punto fundamental eclesiológico es la doctrina de la gracia, de modo que en ese clima eclesial la doctrina sobre Cristo es igual a su influjo en el hombre justificado, es decir, a la doctrina de la gracia. Un texto del Comentario a la carta a los Romanos establece una identificación que clarifica el efecto de la gracia, al que el Angélico destaca como más importante, y por tanto representa el aspecto bajo el cual mira su doctrina sobre la Iglesia: "Evangelio es lo mismo que buena noticia. En efecto, en él se anuncia la comunión del hombre con Dios, que es el bien del hombre"32. Por una parte, el evangelio es Cristo y su gracia santificadora y, por otra, comentando el término "evangelio", señala que lo anunciado en él es la comunión con Dios (coniunctio ad Deum). El texto, plantado al principio de la carta a los Romanos -que según Santo Tomás trata de la gracia en sí- es todo un programa. La doctrina sobre la gracia de Cristo se equipara aquí a la coniunctio ad Deum, sustituyendo con esta expresión el término gratia, que empleó en el prólogo ${ }^{33}$. En este texto, que llamamos programático, ha resumido la doctrina eclesiológica de las cartas, reduciéndola a la unión a Dios - coniunctio ad Deum ${ }^{34}$-, según el modelo, Cristo, y mediante una asimilación a El, que aparecerá en todo su esplendor en el cielo.

29 Ad Heb 5,9.

30 Ad Heb 13,10.

31 "ut pararet nobis viam... corpus enim debet sequi Caput suum" (Ad Heb 9,24).

32 Ad Rom 1,1.

33 Esta sustitución no resulta extraña, ya que para el Angélico el fin de la gracia es la unión a Dios: "Finis autem gratiae est ut coniungat nos Deo" (In III Sent. dist. 13, q. 1, a. 2, sol. 1).

34 Grabmann señala cómo esta idea de la unión a Dios por la gracia es fundamental para la comprensión de la teología medieval en su doble dirección de escolástica y mística. Según él en ella consiste la esencia del cristianismo: «Zugleich ist diese Lehre von der Einheit des Menchen mit Gott durch die Gnade eine grundlegende Idee fur die Auffassung, welche die christiche Theologie des Mittelalters, in ihrem beidem Hauptrichtungen: Scholastik und Mystik von Wesen des Christentums gehabt und ausgesprochen hat» (M. Grabmann, op. cit., p. 76). Aplicándola a la visión de Santo Tomás sobre la Iglesia, afirma Congar: «L'Eglise est foncierement et principa- 
Toda la finalidad del evangelio, por tanto, consiste en manifestar y llevar al hombre a esta comunión con Dios, que es triple: la primera, realizada en el Verbo Encarnado, es modelo y razón de todas las demás. En la segunda, hay que destacar el término "adopción", empleado para indicar el modo de unión del hombre a Dios. El Aquinatense ha preferido expresar la más honda raíz del por qué de esta unión: la semejanza con el Hijo en la filiación. Por último, la unión propia del estado definitivo: la gloria. En este texto, que nos parece programático, ha resumido la doctrina eclesiológica de las cartas, reduciéndola a la unión a Dios -coniunctio ad Deum ${ }^{35}$-, según el modelo, Cristo, y mediante una asimilación a Él, que aparecerá en todo su esplendor en la vida eterna.

La gracia tiene un único origen, el amor de $\operatorname{Dios}^{36}$, con lo que expresa que la iniciativa de la unión con Dios tiene su fundamento en la caridad permanente, que Dios tiene a su creatura ${ }^{37}$. En Cristo-nos dice-se encuentra la plenitud de gracia y de Él deriva a nosotros ${ }^{38}$, haciéndonos hijos adoptivos ${ }^{39}$, de modo que seamos conformes a la imagen del Hijo que, a su vez, es Imagen del Padre ${ }^{40}$. Participamos así de su herencia ${ }^{41}$, ya que si somos hijos en el Hijo, también en Él somos herederos ${ }^{42}$, y así obtendremos la definitiva unión a Dios por la gloria $^{43}$.

lement union avec Dieu en sa divinité: dans le ciel, gloire et vision; ici-bas, grâce et foi» (J.-M.Y. Congar, L Église de Saint Augustin, p. 233).

35 Grabmann señala cómo esta idea de la unión a Dios por la gracia es fundamental para la comprensión de la teología medieval en su doble dirección de escolástica y mística. Según él en ella consiste la esencia del cristianismo: "Por tanto esta enseñanza de la unión del hombre con Dios por la gracia es la idea básica de quienes opinan que la teología de la Edad Media ha mantenido y se ha pronunciado acerca de la esencia del cristianismo en sus dos direcciones fundamentales: la escolástica y la mística” (M. Grabmann, Die Lehre des heiligen Thomas, p. 76). Aplicándola a la visión de Santo Tomás sobre la Iglesia, afirma Congar: "La Iglesia es fundamentalmente y principalmente unión con Dios en su divinidad: en el cielo, gloria y visión; aquí abajo, gracia y fe" (J.-M.Y. Congar, L'Église de Saint Augustin, p. 233.

36 "Ponitur gratiae origo, quod est Dei dilectio" (Ad Rom 1,7).

37 En este aspecto es significativo el título de la obra citada de Grabmann: La Iglesia "como obra de Dios": "als Gotteswerk".

38 "Sic enim a Deo gratia in multos effunditur, ut eam per Christum accipient, in quo omnis plenitudo gratiarum invenitur" (Ad Rom 5,15). "Et tunc dictur illuminat omnem hominem venientcm, per fidem, in hunc mundum, spiri tualem, scilicet Ecclesiam, illuminatam lumine gratiae" (In Io. Evang. 1,9).

39 “...nos ex sola gratia... praedestinamur ut simus filii adoptivi” (Ad Rom 1,4).
40 Ad Rom 8,29.
41 Ad Rom 8,29.
42 Ad Rom 5,2.
43 Ad Rom 1,1. 
Dada la importancia capital del tema, se nos imponen unas constataciones al término de este apartado. La doctrina eclesiológica del Aquinatense se concreta en una doctrina sobre la gracia en estrecha relación con Cristo, en cuanto que somos hijos en Él y bajo el claro aspecto de la comunión con Dios. La deducción se impone, pero las dificultades no son pequeñas, ya que, siendo la gracia una relación personal con Dios ¿ dónde queda el aspecto comunitario? Sin embargo es un punto del que tenemos que partir, porque es el que con más insistencia nos ofrece el Angélico. Ya tendremos ocasión de solventar esta aparente contradicción. Ahora sólo interesa ver los puntos claves de su eclesiología. Pero dejemos constancia -ya desde ahora- de que Santo Tomás describe a la Iglesia como la asamblea de los fieles (congregatio/coetus/collegium/collectio... fidelium $)^{44}$.

\subsubsection{Los sacramentos y el ministro}

La Humanidad de Cristo aparece en el pensamiento de Santo Tomás como el medio, a través del cual conseguimos la unión con Dios. Dentro de la estructura orgánica, que él ve en las cartas de San Pablo, las dirigidas a los Corintios y Gálatas tratan de los sacramentos y del ministerio por la estrecha relación que tienen con la gracia, en cuanto instrumentos de su donación en claro paralelismo con la Humanidad de Cristo. De modo sintético desarrollaremos su doctrina.

Los sacramentos "corresponden a la salvación de los hombres" 45 , y en ellos la virtud divina opera secretamente la salvación ${ }^{46}$. En todo sacramento -dicehay que considerar: el mismo sacramento, la res significada y contenida, es decir, la gracia, y por fin la res significada, pero no contenida, o sea, la resurrección ${ }^{47}$. Gracia y resurrección están, pues, vinculadas a los sacramentos, entendiendo por gracia no sólo la santificante, sino también la gratis data, pero la primera supera a la segunda, como la caridad, que acompaña inseparablemente a la gracia, supera a los otros dones ${ }^{48}$.

Distingue santo Tomás un doble poder de Cristo en el sacramento: uno divino e incomunicable, común a las Tres Personas Divinas, y otro, propio de

44 I Ad Cor 5,4; Ibidem 11,22; I Ad Tim 1,1; In Symb. Exp. art. 9... También la llama "adunatio fidelium": I Ad Tim 3,15; Ad Heb 3,3.

45 I Ad Cor Prol.

46 "divina virtus secretius operatur salutem" (I Ad Cor 4,1).

47 "Primo quidem ipsum sacramentum..., secundo id quod est res significata et contenta, scilicet gratia; tertio id quod est res significata et non contenta, scilicet gloria resurrectionis" ( $\mathrm{Ad}$ Cor 1,10).

48 I Ad Cor 13,1. 
su Humanidad, que es la potestad de excelencia ${ }^{49}$.La auctoritas propia del ministro le viene de que obra in persona Christi $i^{50}$, pues lo que él realiza no es suyo, sino de Cristo-Dios ${ }^{51}$, y por eso sólo Él puede obrar en el interior del hombre, no el ministro ${ }^{52}$. Intermediario entre Dios y los hombres ${ }^{53}$, es el ministro de la reconciliación en Cristo Jesús ${ }^{54}$.

Al sacramento están ligados -es afirmación suya-tanto la gracia "gratis data" como la gracia "gratum faciens", con lo que insinúa el Angélico que la Iglesia se estructura sacramentalmente tanto en su aspecto intimo -gracia gratum faciens, es decir, coniunctio ad Deum-, como en la realidad exterior -gracia gratis data, o sea, unión a Dios "quantum ad actum ipsius Dei"-, aunque no de la misma manera. Sin embargo la "gloria de la resurrección" -el estadio definitivo de la Iglesia-, aunque significada por el sacramento, no está contenida en él, luego el estatuto sacramental no pertenece a ese estadio definitivo eclesial. Por tanto este estatuto no atañe esencialmente a todos los estadios de la realización eclesial; en cambio el aspecto de unión a Dios sigue siendo válido en la resurrección, es más, entonces es cuando se da en plenitud. Por tanto, en los distintos estadios de la Iglesia el elemento permanente y común a todos ellos es la gracia en cuanto coniunctio ad Deum.

\subsubsection{La "unidad de la Iglesia" como efecto de los beneficios divinos}

En el Prólogo general propone el Aquinatense un desarrollo de la unidad de la Iglesia como efecto de la gracia de acuerdo con la materia de las cartas a los Efesios -donde trata el tema con más amplitud-, a los Filipenses, Colosenses y I y II a los Tesalonicenses. En el comentario a la carta a los Efesios, dice que "en lo dicho anteriormente recuerda el Apóstol los beneficios divinos,mediante los cuales se constituye y se conserva la unidad de la Iglesia" ${ }^{25}$. Estos beneficios

49 "Christus in sacramento baptismi duplicem habet virtutem sibi propriam. Unam quidem divinam qua simul cum Patre et Spiritu Sancto interius mundat a peccato, ct hoc nulli creaturae potuit communicari. Alia autem est propria virtus secundum humam naturam, quae est potestatas excellentiae in sacramentis" (I Ad Cor 1,13).

50 II Ad Cor 2,10; ibidem 13,4.

51 II Ad Cor 4,7.

52 I Ad Cor $1,12$.

53 II Ad Cor 5,13.

54 II Ad Cor 5,18.

55 "Supra (se refiere a todo lo dicho anteriormente desde el principio) commemoravit Apostolus divina beneficia, per quae unitas Ecclesiae constituitur et conservatur" (Ad Eph 4,1). Para este tema, conf. J. Ti-Ti Chen, La unidad de la Iglesia. 
son: la predestinación divina para la filiación adoptiva por el Hijo natural ${ }^{56}$; la Redención, por la cual se abolió el pecado ${ }^{57}$; el anuncio del evangelio, que proclama el sumo bien y la vida eterna ${ }^{58}$; el sello del Espíritu Santo, que es espíritu de promesa y pignus haereditatis ${ }^{59}$; el ser constituido como pueblo, que Cristo se adquirióo ${ }^{60}$; la fe y la caridad ${ }^{61}$; la exaltación de Cristo por la cual es constituido Cabeza de la Iglesia ${ }^{62}$; la otra vida con su abundancia de bienes ${ }^{63}$. Todo lo cual -añadirá- es obra del amor ${ }^{64}$. Como puede comprobarse, por ser fiel al texto paulino, entremezcla sin especificar elementos que constituyen la misma unidad, junto a otros que son su causa. Se trata no obstante de ofrecernos todo un cuadro completo de lo que el amor de Dios ha hecho para constituirse un pueblo liberado del pecado y en comunión viva con Él.

Un poco más adelante - en el comentario a la misma Carta a los Efesiosofrece un texto, en el que resume su concepto de unidad ${ }^{65}$, y propone unos elementos comunes a todos los fieles y otros que son específicos de algunos miembros. Elementos comunes son: un mismo Jefe, Cristo; una misma ley, una fe, unos signos idénticos-los sacramentos-, y un mismo fin, Dios ${ }^{66}$. Hay en la Iglesia -añade- diversidad de gracias, de modo que, aunque no se distribuyan uniformemente, todos sin embargo participan de ellas según la voluntad de Cristo ${ }^{67}$. Entre estas gracias se fija, siguiendo a San Pablo, en aquellos que os-

56 “...quia nihil consequitur participationem alicuius, nisi per id quod est per naturam suam tale, ideo adoptionem filiorum oportet fieri per Filium naturalem” (Ad Eph 15).

57 Ad Eph 1,7.

58 Ad Eph 1,13.

59 Ad Eph 1,13.

60 "Christus autem acquisivit popullum ex Gentibus et ideo impressit eis signum acquisitionis" (Ad Eph 1,14).

61 Ad Eph 1,15.

62 Ad Eph 1,22.

63 Ad Eph 2,7.

64 "ubi sciendum est quod quidquid est in mysterio redemptionis humanae et incarnationis Christi, totum est opus caritatis" (Ad Eph 3,19).

65 "Supra (se refiere a lo dicho en el cap. IV) monuit Apostolus ut manerent in ecclesiastica unitate, describendo modum eius et formam (Ad Eph 4,17).

66 "Primo, quia habet ducemn unum, scilicet Christum... Secundo quia lex est una Lex enim ecclesiae est lex fidei... Tertio eadem sunt insignia ecclesiae scilicet sacramenta Christi... Quarto in ecclesia est idem finis, qui est Deus. Filius enim ducit nos ad Patrem" (Ad Eph 4,5-6).

67 "Supra ostendit Apostolus ecclesiasticam unitatem quantum ad id quod in ecclesia est communis, hic ostendit idem quantum ad hoc quod est singulis fidelibus membris ecclesiae proprium et speciale... Dicit ergo: Habemus in ecclesia unum Deum, unam fidem... sed tamen diversas gratias diversis particulariter collatas habemus, quia unicuique nostrum data est gratia, quasi dicat: Nullus nostrum est qui non sit particeps divinae gratiae et communionis... Sed certe 
tentan el ministerio ${ }^{68}$, porque al proponer la verdadera doctrina destruyen la falsa, que rompe la unidad ${ }^{69}$. Es importante subrayar que Santo Tomás no ve en esta unidad algo extático, sino una clara dinámica de crecimiento con un aumento progresivo de la fe, esperanza y caridad, y todo ello como efecto del actual influjo de su Cabeza, Cristo ${ }^{70}$. Su crecimiento sólo tendrá término en la escatología, fin al que tiende la acción santificadora del ministerio, la consumación de los santos y la edificación de la Iglesia ${ }^{71}$.

El Aquinatense establece una distinción entre los dones comunes y los específicos, que reciben los fieles. Los comunes están representados, además de Cristo y los sacramentos, por la ley de la fe y la misma finalidad, Dios, al cual en definitiva nos unimos por la caridad. Los específicos tienen dos niveles: el modo concreto de participar cada uno de los dones -mayor o menor unión a Dios-, y la gracia gratis data, que cada uno ha recibido, es decir, su situación concreta dentro del cuerpo eclesial. Así aparece la diversidad en la unidad fundamental, o sea, la nacida de la caridad y que hace posible que las distintas situaciones concretas colaboren a la unidad de la Iglesia, ya que las gracias "gratis datas" no se dan en beneficio propio, sino en función de todo el cuerpo.

Todos los elementos anteriormente dichos son necesarios para la específica unidad eclesial, y ninguna solución que los menospreciara o disminuyera, estaría de acuerdo con el pensamiento de Santo Tomás. Sin embargo hay graduación en los dones, y entre todos ellos sobresale la caridad, cuya propiedad es unir $^{72}$. Por esta razón la unidad esencial de la Iglesia consiste en la unión a Dios ${ }^{73}$, que desborda en la unión que se establece entre los miembros y que es como manifestación de esa unidad primera ${ }^{74}$. Amor a Dios y amor al prójimo -doble aspecto de la unitas Ecclesiae- mutuamente se incluyen como

ista gratia non est data omnibus uniformiter seu aequaliter, sed secundum mensuram donationis Chlisti, id est secundum quod Christus est dator, et eam singulis mensuravit... Haec differentia non est ex fato, nec a casu, nec ex merito, sed ex donatione Christi, id est secundum quod Christus nobis commensuravit. Ipse enim solus recipit spiritum non ad mensuram, Io, III, 34; caeteri autem sancti ad mensuram recipiunt. Quia sicut in potestate Christi est dare vel non dare, ita dare tantum vel minus" (Ad Eph 4,7).

68 Ad Eph 4,11.

69 Ad Eph 4,14-15.

70 Ad Eph 4,15-16.

71 "Usque ad hoc extenditur praedictum ministerium et consummatio sanctorum et aedificatio ecclesiae, donec in resurrectione occurramus Christo" (Ad Eph 4,13).

72 "Proprium amoris est unire" (Ad Heb 10,25).

73 "Caritate unimur ei" (Ad Col 1,4).

74 "Licet caritas principaliter inhaereat Deo, tamen manifestatur per caritatem proximi" (Ad Heb 10,24). 
causa y efecto ${ }^{75}$. No obstante debe quedar bien claro que es la unión a Dios -coniunctio ad Deum - la que posibilita la unión de los miembros entre si ${ }^{76}$.

\subsubsection{Para terminar este apartado, vamos a deducir unas conclusiones}

a) Una primera constatación es que toda la doctrina del Comentario a las Cartas de San Pablo tiene una esencial e interna referencia a la Iglesia, como se deduce del esquema que propone en el Prólogo General, y más concretamente en la comparación que establece con el cuerpo.

b) Dato fundamental para estructurar toda la materia eclesiológica de santo Tomás es la gracia, en cuanto que por ella se da la "comunión con Dios". En el concepto de gracia se incluye tanto la gratum faciens como la gratis data, aunque esta última lleva sólo a la unión en cuanto a la "acción del mismo Dios", mientras que la primera entraña la unión "al mismo Dios".

c) Si el Angélico considera la gracia en su aspecto eclesiológico bajo la dimensión de la unión con Dios (que llega a su culmen en la gloria) hemos de afirmar que es la gracia gratum faciens la que, por unir a Dios directamente, constituye el elemento primario de la Iglesia, quedando los carismas (gracias gratis datae) en un segundo lugar, instrumental y provisorio en cuanto que sólo pertenecen al estadio terreno de la Iglesia.

d) En la donación de la gracia hay una clara jerarquía: Dios (causa principal) y los instrumentos. Como instrumento primordial aparece la $\mathrm{Hu}-$ manidad de Cristo y sus misterios en razón de su unión al Verbo. Posee la potestas excellentiae y es la Cabeza, de la cual fluye la gracia a todo el Cuerpo. Como instrumentos derivados: los sacramentos y el sacerdocio ministerial.

e) En cuanto a la unidad eclesial podemos anticipar que comporta unos elementos externos (la estructura de la Iglesia) y otros internos, entre los cuales destaca la caridad, que acompaña siempre a la gracia santificante - gratum faciens-, y que estructura en unidad a las diversas gracias gratis datas. La caridad tiene un doble objeto: Dios y los demás miembros, y es su relación a Dios la que posibilita la unidad entre los miembros eclesia-

75 "Sed dicendum est quod illa dilectio proximi ad caritatem pertinet, et legem implet, qua proximus diligitur propter Deum; et ita in dilectione proximi includitur dilectio Dei, sicut causa includitur in effectu... Et e converso, dilectio proxirni includitur in dilectione Dei, sicut effectus in causa" (Ad Rom 13,8).

76 "La Iglesia, en su realidad más profunda, que es también por lo que ella conoce su extensión más total y por lo que permanece eternamente, es comunión con divinizante con Dios" (J.-M.Y. Congar, L'Église de Saint Augustin, p. 232-233). 
les. De donde esta última unidad tiene su origen fontal en la "comunión con Dios".

\subsection{Por que no escribió el Angélico un tratado sobre la Iglesia}

La riqueza eclesiológica de santo Tomás, apenas esbozada en esta síntesis, obliga a los autores a preguntarse por que no escribió un tratado sobre la Iglesia. No puede tomarse como tal la parte eclesiológica de su Expositio in Symbolum, porque -según Vauthier- se trata sólo de sermones cuaresmales, predicados en Nápoles en $1273^{77}$. Por eso la pregunta sigue en el aire. Desde diferentes puntos de vista se ha intentado dar solución a este problema. Schmaus piensa que no lo escribió, porque no se reflexiona expresamente sobre una cuestión teológica, si no es previamente atacada, y en tiempos de Santo Tomas no había herejías propiamente eclesiológicas ${ }^{78}$. El pensamiento de Congar podemos resumirlo de esta manera: el Angélico comienza una nueva investigación cada vez que encuentra una nueva forma relativa a nuestra vuelta a Dios. Ahora bien, la Iglesia no es una nueva forma, sino que su contenido propio está incluido en el desarrollo de las materias, que tienen su lugar especifico en la Suma ${ }^{79}$. Cercano al pensamiento de Congar, Le Guillou piensa que la Iglesia en el Aquinatense no es otra cosa que el desarrollo del misterio de la salvación y esto es lo que realiza en toda su obra teológica ${ }^{80}$. Creo que la razón más profunda estriba en su modo peculiar de mirar a la Iglesia, no como un elemento más al lado de otros, sino como "la ley arquitectónica" (Grabmann) del gran edificio teológico ${ }^{81}$. Esta visión responde a la óptica de toda la teología medieval, para la cual, en estricta dependencia de los Padres, la Iglesia es el clima donde se vive, la realidad inmediata donde se participa del misterio de Dios en Cristo por el Espíritu Santo. Sólo se romperá esta visión, cuando por razones apologéticas se busque defender algún punto concreto, como es el caso de Jacobo de Viterbo o Torquemada.

Podemos afirmar que la eclesiología en la estructura teológica de Santo Tomas se identifica con el desarrollo de toda su teología. La Iglesia es la comunión con Dios por la gracia, y en sentido instrumental es el lugar -no como espacio- donde el hombre es alcanzado eficazmente por la Palabra y el Sacramento.

\footnotetext{
77 E. Vauthier, Le Saint-Esprit, p. 195. Cfr. I. Bermejo, Santo Tomás y la Iglesia.

78 M. Schmaus, Teologia dogmática.

79 J.-M.Y. Congar, Traditio thomistica, p. 411; Igualmente podemos citar a R. Velasco, La Iglesia en la Tercera, p. 110, que sigue a Th.M. Kaepelli, Zur Lehre des hl. Thomas, p. 2.

80 M.J. Le Guillou, Le Christ et l'Eglise.

81 M. Grabmann, Die Lehre des heiligen Thomas, p. 5.
} 
Como esta unión llega a su culmen en la gloria, de aquí que llame a ese estadio de la Iglesia vera Ecclesia ${ }^{82}$. Para el Angélico la Iglesia es impensable sin un desarrollo de la propia vida intratrinitaria, ya que de ahí arranca su propio ser. No se entiende sin un conocimiento serio del papel de la Encarnación, como camino para llegar a la comunión con Dios. Por eso, al ser la Iglesia el momento catalizador sobre el que incide todo lo demás, desarrollando su esquema teológico, está proponiendo lo que ella es.

La Iglesia es el sacramentum, espacio eficaz, el clima donde se realiza y se vive la comunión con Dios. La ausencia de un tratado sobre la Iglesia no es un olvido o una laguna como dice Darquennes ${ }^{83}$, sino que implica una concepción de su propio ser, de su propia naturaleza: comunión vital con Dios y en Él y por Él con los demás hermanos. La mirada penetrante del Angélico ha llegado al fondo del tema, donde los modelos de Iglesia corresponden únicamente a la sociología. Porque la visión eclesiológica de Santo Tomas es netamente teológica: referencia esencial a Dios. De aquí su esquema eclesiológico y su distinción neta entre la naturaleza de la Iglesia y los diferentes estadios de su realización concreta.

Mucho se ha discutido -Chenu, Lafont, etc.- sobre la estructura de la Suma Teológica, en cuyo esquema, como obra cumbre sintética, aparece su concepción de la teología. Se impone, como conclusión, las categorías del exitus y del reditus: creados por Dios, somos llamados a la comunión escatológica y plena con $\mathrm{E}^{84}$. Pues bien, en el proceso del reditus se insertan los medios para la consecución de esta finalidad, y entre ellos, cualificando de algún modo a todos los demás, considera el Aquinatense a la Humanidad de Cristo y a la Iglesia, que es su Cuerpo.

\section{La Iglesia comunión}

Fue el sínodo de 1985 el que dio un especial relieve a la teología de comunión en la eclesiología del concilio. Según este sínodo, "la eclesiología de comunión es la idea central y fundamental en los documentos del concilio [...]. La eclesiología de comunión es el fundamento para el orden de la Iglesia y sobre todo para una justa relación entre la unidad y la pluriformidad en la Iglesia" ${ }^{35}$.Pero

\footnotetext{
82 “... sed celestem, quia ibi est vera Ecclesia, quae est mater nostra et ad quam tendimus et a qua nostra Ecclesia militans est exemplata” (Ad Eph. 3, 10).

83 A. Darquennes, La detinifion de l'Église, p. 3.

84 Cfr. M.-D. Chenu, Introduccion a; G. Lafont, Estructuras y método en la Suma Teológica.

85 Sínodo extraordinario 1985, II C. 1.
} 
la palabra comunión (koinonia), aplicada a la Iglesia, adquirió diversas interpretaciones no siempre justas, de modo que el sínodo extraordinario de 1985, recordando las enseñanzas conciliares, subrayaba que "la eclesiología de comunión no se puede reducir a meras cuestiones organizativas o a cuestiones

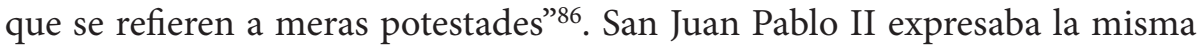
tentación de reduccionismo con estas palabras: "La eclesiología de comunión no puede ser captada adecuadamente cuando se la entiende como una simple realidad sociológica y psicológica" ${ }^{87}$. Recuerda De la Soujeole, en un artículo sobre Santo Tomás, que el concepto de comunión según algunos autores "sugiere la libertad eclesial concebida como liberación de todo lo que la sociedad eclesiástica tiene de apremiante. En fin, se presta a veces a expresar la oposición fácil y engañosa entre la 'vida' y la estructura' (o la institución en la Iglesia)" 88 .

Pero la oposición que supuso el paso del concepto de sociedad (perfecta)al de comunión está lejos del pensamiento de santo Tomás, que utiliza la noción de sociedad en su sentido más genuino. "La eclesiología de Santo Tomás presenta, en efecto, como núcleo profundo y último de la Iglesia, la communio, que no sólo se origina ontológicamente e históricamente en la gracia capital de Cristo -fruto de la encarnación del Verbo y de sus actos redentores- sino que a partir de ella se mantiene como communio por la operación del Espíritu Santo a través de la estructura de la Iglesia" ${ }^{89}$.

\subsection{La Iglesia comunión con Dios}

La Iglesia para el Angélico, es una creación del amor de Dios, que "supera todo entendimiento creado y la ciencia de todos, pues es incomprensible" 90 . Este amor es la única razón que explica que Dios "istam domum, scilicet Ecclesiam, ex nihilo, scilicet ex statu peccati in statu gratiae creavit" ${ }^{11}$. En su naturaleza más profunda, la Iglesia es koinonia, comunión con Dios -coniunctio ad Deum, dirá él-.Ahondando en la expresión "la creó" se deduce que la Iglesia es esencial referencia a Dios, o dicho de otro modo, que su consistencia estriba en su comunión gratuita con Dios, fuera de la cual no es nada.Esta dependencia indica tanto un origen, como una manera permanente de ser y de operar, de tal modo

Ibidem. Cfr. CDF, Carta “Communionis notio" (28.05.1992), n. 1.

87 Juan Pablo II, Chistifideles laici 19.

88 B.-D. De la Soujeole, "Société" e "communion", p. 587.

89 P. Rodríguez, La Iglesia como 'communio', p. 300.

90 Ad Eph 3,19.

91 Ad Heb 3,3. "infusio gratiae est quaedam creatio" (II Ad Cor 5,17).
} 
que la realidad de la gracia incluye, como dato esencial, la continua dependencia de Dios. Por eso en la unión a Dios -efecto de la gracia y dato esencial de la Iglesia- no sólo Él tiene la iniciativa, sino que es el fundamento permanente de su posibilidad. De aquí que la Iglesia, en su ser más íntimo, es absoluta y total referencia a Dios.

¿Cómo se realiza esta creación de la Iglesia? Dios, que no tiene acepción de personas ${ }^{92}$, "ab aeterno praedestinavit... ex tempore vocat... sanctificat" 93 . Comenta las palabras de S. Pablo "elegit nos", e indica: quiénes participan de la Iglesia("todos los santos desde el principio del mundo"); el fin de la misma("la salvación eterna"); el medio para conseguirla("por la gracia santificante"), y la necesidad de nuestra respuesta("el consentimiento del libre albedrío por la $(\mathrm{fe})^{\prime 9}$. Al acto creativo de la Iglesia por Dios, mediante el cual establece su unión de amor con el hombre, son llamados todos los santos desde el principio del mundo, es decir, todos aquéllos que libremente respondieron en fe y recibieron la gracia santificante ${ }^{95}$. A la Iglesia, por tanto, pertenecen todos cuantos desde el principio respondieron a la llamada de Dios.

Esta comunión con Dios -raíz la más profunda de la visión comunional de la Iglesia- se realiza a nivel de las tres Divinas Personas, porque la posibilidad y el hecho de que el hombre llegue a la unión con Dios hunde sus raíces en el mismo seno de la Santísima Trinidad: dado que el Verbo es Luz y Sabiduría del Padre, el hombre puede conocerle; porque el Espíritu Santo es Amor de ambos, el hombre puede amar a Dios y a los otros. Si la comunión con Dios tiene su rigen en la Trinidad, desde el punto de vista antropológico, Santo Tomas se plantea la comunión con Dios, partiendo de una afirmación rotunda: "Numquam tamen perficietur natura humana, nisi in coniunctione ad Deum" "96, pues sólo entonces "alcanzará su perfección por la unión a Dios como a su objetivo, en el cual únicamente consiste la bienaventuranza”.

Esta comunión encuentra su punto álgido en la filiación divina, cuyo autor es el Padre, el Hijo es el ejemplar y el Espíritu es quien imprime en nosotros la

92 Ad Gal 2,6.

93 Ad Rom 8,28.

94 "Circa electionem tria tangit. scilicet ordinem electorum, finem electionis, et medium consequendi finem. Electi sunt omnes sancti a principio mundi... Finis item electionis est salus eterna... Hoc autem fit, primo, ex parte Dei per gratiam sanctificantem... secundo, ex parte nostra, est consensus liberi arbitrii per fidem" (II Ad Tess 2,12; Conf. Ad Rom 9,13; Ad Eph 1,7; II Ad Tim 1,9; Ad Eph 1,5; Ad Philip 4,3).

95 Tanto para la comunión vertical (con Dios) como horizontal (entre los hermanos) la noción tomista de participación es de una gran importancia. Cfr. C. Fabro, La nozione metafisica di; F. Ocáriz, Il mistero della Chiesa come Koinonia, p. 158-161.

\footnotetext{
96 Ad Eph 5,1.
} 
imagen del Hijo. Al ser hijos en el Hijo por la acción del Espíritu, los hombres adquieren una nueva relación con la Trinidad, a cuya imagen en definitiva se constituye la Iglesia en comunión vital. Por tanto se establece "una comunión espiritual de los miembros entre sí, consecuencia de su comunión teologal y trinitaria con el Padre, el Hijo y el Espíritu Santo mediante las virtudes teologales (radicadas en la gracia santificante o participación de la naturaleza divina)"97.

Dios no es sólo el autor de la Iglesia, sino también su consumador, en cuanto que la comunión, teniendo en Él su fundamento perenne, culmina en la vida eterna como fin, y así también Dios sólo puede ser entendido como Trinidad ${ }^{98}$. En la unión con Dios por el entendimiento y la voluntad culmina todo el proceso, que la gracia comenzó en el hombre. La dinámica del entendimiento y de la voluntad -presupuesto antropológico-, elevada por la gracia y transformada por las virtudes teologales -dato sobrenatural- llega a su total perfección, y así "anima hominis totaliter requiescat in Deo, et solus Deus sit beatitudo" 99 . La bienaventuranza del cielo consiste en la visión de Dios, y ésta lleva consigo una configuración de los bienaventurados a la Santísima Trinidad: "Patri, ad quem habent accesum, Filio, per quem, Spiritui Sancto in quo accedunt"100. De aquí nace la "communis sanctorum societas" o, como también la llama el Aquinatense, "visio experimentalis pacis"101.

\subsubsection{Por Cristo y en Cristo}

La fundamentación cristológica de la Iglesia abre un amplio y original capitulo en la eclesiología del de Aquino, pues "Christus ipse est totum Ecclesiae bonum" ${ }^{102}$. En primer lugar nos encontramos esta afirmación: "Ad hoc venit in mundum ut Ecclesiam fundaret" 103 , pero, da un paso más. Cristo "en cuanto hombre -afirma- es una vía que nos conduce a Dios"104, es decir, es quien posibilita la unión con Dios. Ahora bien, la Humanidad de Cristo -ratificará- no

97 F. Ocáriz, Il mistero della Chiesa come Koinonia, p. 156.

98 "....sed secundum quod intelligitur in se ipsa, prout videtur a beatis, non potest intelligi sine Trinitate personarum" (STh II-II, q. 2, a. 8, ad 3.).

99 I Ad Cor 15,28.

100 Ad Eph 2,19.

101 Ad Heb 12,22.

102 In IV Sent. dist. 49, q. 4, a. 3, ad 4. "Quoniam totum principium vitae nostrae et operationis est Christus” (Ad Philip. 1, 21). Cfr. R.M. Schmitz, De nexu Christum inter et Ecclesiam iuxta sanctum Thomam, pp. 277-287.

103 In Math 16,18.

104 Christus "secundum quod homo via est nobis tendendi in Deum" (STh I, q. 2, Prol). 
es solamente un medio, ya que entonces sería una condición inherente sólo al estadio visible y peregrinante de la Iglesia, sino que es un elemento permanente de su ser propio. Es cierto que el Aquinatense piensa que, de no haber existido el pecado, la Encarnación no hubiera tenido lugar ${ }^{105}$, pero una vez que Dios lo determinó así106, la Encarnación no es algo contingente y ajeno al ser de la Iglesia, sino algo necesario en todos los estadios de su realización. De aquí que tengamos que interpretar lo que entiende el Santo por el término via aplicado a Cristo, "en cuanto que hombre".

El concepto-clave, del que parte para su reflexión, es el de la capitalidad de Cristo en cuanto a su Humanidad: "Estis membra dependentia de Christo membro, quod quidem dicitur membrum secundum humanitatem secundum quam, praecipue dicitur Ecclesiae caput"107. Este concepto incluye cuatro notas: "conformidad de naturaleza", es decir, el ser verdaderamente hombre ("Christus enim assumpsit naturam sine peccato, sed cum pasibibilitatem, quia assumpsit carnem simili peccatrici") ${ }^{108}$; la plenitud de gracias("sed in Christo est plenitudo omnium gratiarum") ${ }^{109}$; la "preeminencia" en razón de su unión hipostática al Verbo, y su "influencia" en el ser y en el crecimiento de la Iglesia ("ita a capite Christo in caetera membra ecclesiae motus et sensus spiritualis derivatur") ${ }^{110}$.

Para ejemplarizar el influjo de Cristo en la Iglesia, Santo Tomas acudirá al concepto de "instrumento", que al aplicarlo a la Humanidad de Cristo, lo llamará instrumento unido (a la divinidad) o sacramentum coniunctum ${ }^{111}$, y por ello sus acciones son theándricas o deiviriles, según terminología prestada del

105 "Quod non fieret incarnatus si non peccasset homo, in quam partem ego magis declino" ( I ad Tim 1,15).

106 "Quia Deus ordinavit fienda secundum quod res fienda erant" (I ad Tim. 1,15).

107 I Ad Cor 12,27.

108 Ad Heb. 2,14. Y continúa diciendo: "Quod autem hic dicitur quod Christus communicavit carni et sanguini non est intelligendum secundum quod dicunt vitia carnis et sanguinis, quia non assumpsit culpam, nec commisit; sed secundum quod dicunt ipsam substantiam carnis animatae, quia carnem et sanguinem assumpsit. Item est intelligendum de passibilitate carnis, quia assumpsit naturam nostram passibililem. Ut sit sensus quia pueri, idest fideles, habuerunt naturam passibilem, et Ipse, scilicet Christus, participavit eisdem, vel pueri, scilicet in natura carnis et sanguinis, vel eisdem, id est, carni et sanguini, non quidem phantasticae, ut delirat Manichaeus, nec accidentaliter, ut fingit Nestorius, sed similiter, scilicet nobis, id est, eo modo quo participamus, id est secundum rei veritatem, scilicet personaliter et substantialiter. Nos enim participamus ei in persona et Christus etiam similiter assumit ea in unitate personae.." (Ad Heb 2, 14). Este texto pertenece a una inserción hecha por primera vez en 1562 (Venecia) por Remigio Florentino.

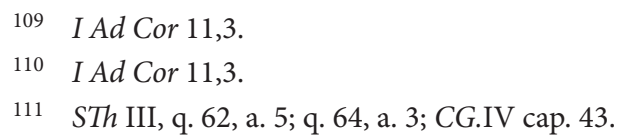


Damasceno $^{112}$. La virtualidad natural de la Humanidad de Cristo, es cierto, queda en los límites de lo humano. Sin embargo, al ser asumida por el Verbo, el efecto que sigue de su actuación supera las limitaciones creaturales para ser realmente divino ${ }^{113}$. El efecto -dice Santo Tomás- tiene alguna semejanza con la causa ${ }^{114}$, y esto hay que interpretarlo, con el propio Santo, refiriéndolo a la causa instrumental, de modo que su ser propio intervenga influyendo en el efecto y plasmando de alguna manera sus propias virtualidades. Ahora bien, la intervención propia de Cristo en cuanto Hombre consiste en el influjo de su gracia capital, porque opera "quasi ex virtute propria" y no como el ministro, cuya gracia personal no se requiere para la eficacia sacramental, ya que obra "ex virtute alterius" (es decir, de Cristo) ${ }^{115}$.

La Humanidad de Cristo se une instrumentalmente a la acción del Verbo en última instancia por su voluntad humana ${ }^{116}$ totalmente sometida a la de Dios, en cuanto que con el Verbo forma una sola Persona. En el primer acto de su voluntad está contenida toda la obra redentora y toda la Iglesia, como en su origen, aunque su realización concreta depende de los misterios de la vida de Cristo, especialmente de su muerte y resurrección. Con su muerte Cristo

112 San Juan Damasceno, De fide orthodoxa, III, 15 (PG. 94, 1060 A). Sobre la causalidad instrumental de la Humanidad de Cristo, cfr. E. Hugon, La causalité instrumentale; H. Boüesse, La casualité efficiente instrumentale; J. Lécuyer, La casualité efficiente des mystéres; J. Geiselmann, Christus und die Kirche, pp. 198-222; M. Lavaud, Saint Thomas et la causalité efficiente instrumentale.

113 "(Humanitas Christi) assumpta est ut instrumentaliter operetur ea quae sunt operationes proprie solius Dei, sicut est mundare peccata, illuminare mentes per gratiam et introducere in perfectionem vitae aeternae" (CG.IV, cap. 41).

114 Ad Rom 4,25. Principio que aplica en este caso concreto a la Humanidad de Cristo, y aún más concretamente a los misterios de su muerte y resurrección. He aquí el texto completo: "Et ideo dicendum est quod mors Christi fuit nobis salutaris, non solum per modum meriti sed etiam per modum cuiusdam cfficientiae. Cum enim humanitas Christi esset quodammodo instrumentum divinitatis eius, ut Damascenus ait, omnes acciones et passiones humanitatis Christi fuerunt nobis salutiferae, utpote ex virtute divinitatis provenientes. Sed quia effectus habet aliqualiter similitudinem causae, mortem Christi qua extincta est in eo mortalis vita, dicit esse causam extinctionis peccatorum nostrorum; resurrectionem autem eius qua redit ad novam vitam gloriae, dicit esse causam iustificationis nostrae, per quam redimus ad novitatem iustitiae".

115 "Ad tertium dicendum, quod minister Ecclesiae non agit in sacramentis quasi ex propria virtute, sed ex virtute alterius, scilicet Christi; et ideo in eo non requiritur gratia personalis, sed solum auctoritatis ordinis, per quam quasi Christi Vicarius constituitur. Christus autem operatus est nostram salutem quasi ex propria virtute, et ideo oportuit quod in eo esset gratiae plenitudo" (De Verit. q. 29, a. 5, ad 3).

116 "Sic ergo humana natura in Christo fuit instrumentum Divinitatis, ut moveretur per propriam voluntatem" (STh 1II, q. 18, a. 1, ad 2). 
satisfizo por nuestros pecados ${ }^{117}$, destruyéndolos ${ }^{118}$, y nos unió a Dios ${ }^{119}$, al ofrecerse a sí mismo al Padre como Pontífice y Víctima y ejercitando su oficio de Mediador ${ }^{120}$. Con este doble aspecto -destrucción del pecado y unión a Dios- se afirma la totalidad de la obra redentora, llevada a cabo por Cristo en la cruz, y por esta razón él se adquiere un pueblo ${ }^{121}$, es decir, la Iglesia, nacida de su costado abierto ${ }^{122}$.

El influjo de la Humanidad de Cristo es "casi por virtud propia" y no como la del ministro sacerdotal. Por ello, santificada por su unión al Verbo, es en grado eminente santificadora, plasmadora de su propia santidad. Las consecuencias de estas afirmaciones se concretan en dos tesis correlativas: la Humanidad de Cristo es el ejemplar de la Iglesia, y ésta es la ejemplada de Aquél. Veámoslo.

Un rasgo propio del instrumento-sacramento es que deja una cierta impresión en el efecto, nacida de su misma acción ${ }^{123}$. Al tratarse de la Humanidad de Cristo -instrumento unido a la divinidad- esta marca es interna, en el orden de la gracia, de modo que se convierta en el ejemplar de la Iglesia, o dicho de otro modo, que la constitución de ésta -su propio ser- se configura según el modelo de la Humanidad de Cristo: "Corpus Christi verum est exemplar corporis mystici" 124 . No se trata, por tanto, sólo de una influencia mediadora sino también asimiladora. Santo Tomas no ha hecho otra cosa sino desarrollar el

117 Ad Rom 3,25.

118 "Sed mors Christi est destructiva peccati" (Ad Heb 9,28).

119 "Perfecit, quod fecit reconciliando et coniungendo nos Deo tanquam principio" (Ad Heb $10,14)$.

120 "In Christo autem est duplex natura: una scilicet divina, secundum quam est Verbum Patris; alia est humana, secundum quam est pontifex offerens se in cruce" (Ad Heb 4,12; 5,7; 12,24; 13,10; I Ad Tim 2,5-6; Ad Gal 3,20).

121 "Ad quid autem signati sumus, subdit, dicens «in redemptionem». Nam si aliquis de novo aliqua animalia acquireret et adderet gregi suo, imponeret eis signa acquisitionis illius. Christus autem acquisivit populum ex Gentibus... Et ideo impressit eis signum acquisitionis... Sed quia Christus acquisivit populum istum, non sic quod numquam fuerit suus, sed quia aliquando fuerat suus, sed opprimebatur servitute diaboli, in quam peceando se redegit, ideo non dicit simpliciter acquisivit, sed addit «in redemptionem», quasi dicat: Non simpliciter de novo acquisivit, sed quasi a servitute diaboli per sanguinem eius redemit... Acquisivit ergo Christus nos redimendo non quod accrescat inde aliquid Deo; quia bonorum nostrorum non indiget" (Ad Eph 1,14).

122 "Et quia de latere Christi dormientis in cruce fluxerunt sacramenta sanguinis et aquae, a quibus fabricata est Ecclesia" ( I Ad Cor 11,7).

123 "Omne agens instrumentale exequitur actionem principalis agentis per aliquam actionem propriam et connaturalem sibi... Effectus autem respondens actioni proprie instrumenti est prior in via generationis quam effectus respondens principali agenti" (CG, II, cap. 21). Al hablar de la muerte y resurrección de Cristo, enuncia este principio: "Quia effectus similitudinem causae habet aliqualiter" (Ad Rom 4,25).

124 Ad Eph 4,13. 
tema paulino en Christo, que no es sólo una asimilación o ejemplaridad conseguida mediante Cristo, sino en analogía con el "ser-en" de su Humanidad. Este es el sentido más primario y profundo de la imitatio Christi, que no se agota en una moral de seguimiento por empeñativa que sea, sino que llega al plano de lo ontológico. Aquí está la razón principal de por qué la Iglesia, la gracia, etc. son cristianas. No solamente porque nos vienen a través de Cristo, sino porque nos configuran ontológicamente a su propia Humanidad.

Es cierto que la comunión en Cristo y por Cristo es personal pero en modo alguno esta dimensión se contrapone en el Angélico al aspecto comunitario. Es todo el cuerpo de la Iglesia el que re-presenta -en su sentido fuerte- a su Humanidad santificada, de modo que la perfección eclesial como su ejemplada consiste en ser un cuerpo ex multis, representativo de las riquezas inagotables de Cristo. La unión a Dios - naturaleza de la Iglesia- se lleva a cabo por Cristo, indicando el único medio a través del cual podemos llegar a esa unión, y en Cristo, testificando la configuración ontológica de la Iglesia -no sólo moral- según el exemplar de la Humanidad de Cristo. La Iglesia es el cumplimiento de lo que Cristo es y representa, es decir, la redención "in actu secundo", manifestando -cuerpo en el sentido hebraico- lo que es y realiza -no sólo realizó- Cristo. Así ella es, según el modelo -exemplar- de Cristo en cuanto Hombre, sanctificans y sanctificata, es decir, comunidad de salvados e instrumento de salvación. Los dos datos están inseparablemente unidos, pero de modo que sea el primero el aspecto ontológico primario, que posibilita la realización del segundo.

\subsubsection{En el Espíritu}

Santo Tomás habla frecuentemente del Espíritu Santo en los Comentarios al Corpus paulinum, de modo que apenas hay tema de importancia eclesiológica, que no lo relacione con Él. A veces son pequeños apuntes circunstanciales, aun sin pedirlo el texto comentado, y que indica la importancia que le atribuye desde el punto de vista eclesiológico. Los Orientales se quejan de nuestra deficiente pneumatología eclesial. Un buen capítulo, desagraciadamente aun no plenamente desarrollado, como reconoce Congar en su libro sobre el Espíritu Santo, lo escribió Santo Tomas. Al Espíritu Santo lo llama "Alma de la Iglesia"125. He aquí en esquema su pensamiento.

Momento cristológico fundamental -como no podía ser menos- para santo Tomás es el hecho de la Encarnación, porque es entonces cuando se hace la unión in Persona. Sin embargo aún no se ha realizado la redención y Cristo en

125 "Anima autem quae hoc corpus vivificat, est Spiritus Sanctus" (In Symbol. Expos). Cfr. In III Sent. dist. 13, q. 2, a. 2, qla. 3, sol. 2. 
su Humanidad no ha adquirido la exaltación propia de la unión hipostática. La aceptación de la voluntad del Padre hasta la muerte merece que Dios le constituya -en cuanto Hombre- en Hijo de Dios in virtute, sentándolo a la derecha. Es entonces cuando Cristo comunica el Espíritu Santo "copiosius et communius" 126 . Hay por tanto una dependencia entre esta donación del Espíritu y el ser constituido Cristo en su Humanidad, Hijo de Dios in virtute y Cabeza de la Iglesia. En Cristo hay dos naturalezas y a ambas pertenece que Cristo confiera el Espíritu Santo: a la divina, porque es el Verbo y a la humana, porque recibió la suma plenitud de ese Espíritu de modo que de Él se deriva a todos ${ }^{127}$.

De Cristo Cabeza fluye a la Iglesia el gran don del Espíritu Santo, de quien proviene tanto la gracia gratum faciens como la gratis data, los dos aspectos que constituyen a la Iglesia como Cuerpo de Cristo. Decir entonces que el Espíritu es "principio de la gracia" es lo mismo que afirmar que es "principio de la Iglesia". De aquí el aforismo, que repite frecuentemente el Angélico, aunque con diversas formulaciones: "no hay miembro alguno en la Iglesia que no participe de las gracias del Espíritu Santo"128. Su función en ella es inhabitar dinámicamente como gracia que conlleva todos los dones. Distingue el Angélico dos modos de esta inhabitación del Espíritu: en el fiel, derramando en él la gracia santificante, y en la Iglesia como origen de todos los carismas y ministerios. La acción, por ello, del Espíritu se extiende a toda la riqueza carismática de la Iglesia ${ }^{129}$.

\section{Ad Rom 8,2.}

127 "In Christo enim duas naturas invenimus, et ad utramque pertinet, quod Christus det Spiritum Sanctum. Quantum quidem ad divinam, quia est Verbum, ex quo simul et a Patre procedit ut amor. Amor autem in nobis procedit ex conceptione cordis, cuius conceptio est verbum. Quantum vero ad humanam, quia Christus accepit summam plenitudinem eius, ita quod per eum ad omnes derivatur... Et ideo baptismus et alia sacramenta non habent efficatiam, nisi virtute humanitatis Christi” (Ad Tit 3,6).

128 I Ad Cor 12,7. De otro modo: "Sicut enim nullum membrum est in corpore quod non participet aliquo modo sensum vel motum a capite, ita nullus est in Ecclesia qui non aliquid de gratiis Spiritus Sancti participet” (Ad Rom 8,9). O también según la fórmula expresada anteriormente, conf. Ad Rom 8,2.

129 "Manifestatio Spiritus, in quo designatur officium gratiae gratis datae. Pertinet autem ad gratiam gratum facientem, quod per eam Spiritus Sanctus inhabitet quod quidem non pertinet ad gratiam gratis datam, sed solum ut per eam Spiritus Sanctus manifestetur, sicut interior motus cordis per vocem... Manifestatur autem, per huiusmodi gratias, Spiritus Sanctus dupliciter. Uno modo ut inhabitans Ecclesiam et docens et sanctificans eam, puta cum aliquis peccator, quem non inhabitat Spiritus Sanctus, faciat miracula ad ostendendum, quod fides Ecclesiae quam ipse praedicat sit vera... Alio modo manifestatur per huiusmodi gratias Spiritus Sanctus ut inhabitans eum cui tales gratiae conceduntur. Unde dicitur Act. VI, 8, quod Stephanus plenus gratia faciebat prodigia et signa multa, quem Spiritu Sancto plenum elegerunt; sic autem non conceduntur huiusmodi gratiae nisi sanctis" (I Ad Cor 12,7; conf. Ibidem 12,3). 
Ambas gracias - gratis data y gratum faciens- tienen el mismo origen y manifiestan al mismo Espíritu Santo, pero no llevan consigo los mismos efectos en razón de la persona que los recibe, pues para el pecador esta presencia permanece externa a su propia intimidad personal. Aunque sea un bien para toda la Iglesia, la gracia gratis data, como manifestación del Espíritu, puede dejar vacío de gracia interior al pecador, a no ser que se abra interiormente al requerimiento de la gracia actual. San Esteban será el modelo, que aduce el Santo, pues la acción del Espíritu no sólo se manifiesta a través de él sino en su propio interior $^{130}$.

Al mismo tiempo, el Espíritu es la raíz de la unidad eclesial, que es doble: una interior y otra exterior, y las dos son necesarias ${ }^{131}$. A la exterior la llama pax, que interpreta como la mutua relación sin disensiones en el desempeño del propio oficio dentro del Cuerpo Místico ${ }^{132}$; la otra interior tiene su fundamento en el "idem credendo... idem diligendo", es decir, en cuanto que el objeto de la fe y la caridad es el mismo, Dios. La unidad interior -esencia de la Iglesia, fructum salutis- y la exterior -la estructura eclesial, medium salutis- se relacionan intrínsecamente a la manera del cuerpo y el espíritu. Además habla de una tercera y cuarta unidad. La tercera representa un grado más de unión, y la califica como vivificación por la gracia y la caridad. La última de ellas, la cuarta, proviene de la propia Persona del Espíritu Santo y es la última y principal perfección de todo el Cuerpo Místico, como el alma en el cuerpo natural ${ }^{133}$.

La raíz última tanto de la unidad interior -la que constituye a los hombres en vere fratres por vivir de la gracia de la filiación divina- como de la exterior - proveniente de los otros carismas- no puede provenir sino del Espíritu Santo, que al ser uno y el mismo en la Cabeza y en los miembros, no se multiplica en los fieles como sus dones. El Espíritu realiza a nivel eclesial la función que

130 Cfr. I Ad Cor $12,7$.

131 "Est autem duplex unio necessaria ad membra Ecclesiae unienda. Una est interior, ut scilicet idem sapiant per fidem, quantum ad intellectum, idem credendo et per amorem, quantum ad affectum, idem diligendo. Et ideo dicit idem sapite, id est idem sentiatis de fide, et idem diligatis affectu caritatis. Quia tunc est vera sapientia, quando operatio intellectus perficitur et consummatur per quietationem et delectationem affectus. Unde sapientia dicitur, quasi sapida scientia... Alia est exterior, scilicicet pax, et ideo dicit pacem habete inter vos" (II Ad Cor 13,11; conf. Ad Col 2,19).

132 I Ad Cor 14,33.

133 "Et haec quatuor uniones inveniuntur in corpore mystico. Prima est, inquantum omnia membra eius sunt unius naturae vel specie vel genere. Secunda est, inquantum colligata sunt ad invicem per fidem, quia sic continuantur in uno credito. Tertia est, secundum quod vivificantur per gratiam et caritatem. Quarta est, secundum quod in eis est Spiritus Sanctus, qui est ulima perfectio et principalis totius corporis mystici, quasi anima in corpore naturali" (In III Sent. dist 13. q. 2, a. 2, sol 2). 
desempaña en el interior de la vida trinitaria: unir. En resumen, la Persona del Espíritu Santo es la fuente última de la unidad del Cuerpo Místico y quien posibilita, en definitiva, que Cristo sea Cabeza de la Iglesia en su Humanidad. Y esto por dos razones: por el don de las virtudes teologales (y de la gracia), cuyo objeto es uno y el mismo numéricamente, y sobre todo por la inhabitación en el alma de cada justo como "principio interno de unidad numérica".

Con el desarrollo esquemático de la pneumatología eclesial del Aquinatense podemos establecer la siguiente conclusión: la naturaleza de la Iglesia consiste en la comunión con el Padre en y por el Hijo y en razón de la inhabitación dinámica del Espíritu. La Iglesia como misterio de comunión trinitario es la concepción fontal, su naturaleza más intima según Santo Tomas.

La razón de ser comunidad la Iglesia estriba, por tanto, a cualquier nivel de la unidad -de finalidad, causativa, de ejemplaridad y en razón de la inhabitación del Espíritu Santo- en la "comunión con Dios", de la cual deriva la "unidad de los miembros". Y como esta unión con Dios es personal, de aquí la fuerte visión del aspecto personal que tiene el Angélico, la cual no impide sino ennoblece, el aspecto comunitario. La unión a Dios y la unión entre los miembros no son dos momentos temporalmente sucesivos, sino ontológicos, y de los dos el primero es la unidad a Dios, que tiene su expresión máxima en la inhabitación del Espíritu Santo. Por otra parte, esta doble unión -con Dios y de los miembros entre sí- no tiene su origen en la decisión personal del individuo, sino en la acción e inhabitación del Espíritu.

En un primer momento, hemos dicho que la Iglesia es radicalmente "comunión con Dios". En un segundo momento, añadíamos "por Cristo y en Cristo". Al final le agregábamos una definitiva precisión: "en razón de la inhabitación del Espíritu Santo". De este modo la naturaleza de la Iglesia -su misterio- queda formulada así: "Comunión con Dios por Cristo y en Cristo, en razón de la inhabitación del Espíritu Santo". Si leemos Dios por Padre -y tenemos sobrados fundamentos para hacerlo, ya que la causa de la unión es la filiación adoptiva- obtendremos esta última síntesis sobre el ser de la Iglesia: "Comunión con el Padre Dios por Cristo y en Cristo, en razón de la inhabitación del Espíritu Santo"134. El proceso interior trinitario -"teología"- se hace eclesiología -"economía"- por la inhabitación del Espíritu Santo, que forma en nosotros la imagen del Hijo y nos lleva al Padre. 


\section{Dos cuestiones finales}

\subsection{La Iglesia "mysterium-sacramentum"}

El Concilio Vaticano II llama a la Iglesia "sacramentum"135, y esta afirmación del magisterio solemne, dada su importancia, es una buena razón para ver qué aporta el Angélico en este tema ${ }^{136}$, aunque ya hemos conocido algunos elementos que llevan a una conclusión positiva. Partimos de la definición de sacramento que da ensu Comentario de la primera carta a los Corintios: el término "sacramento" expresa "secreto" y también "sacrae rei signum, ita quod et eius imaginem gerat, et causa existat"137. El Aquinatense emplea siempre el término "sacramentum", cuando se refiere a los del Antiguo Testamento o a los siete de la Iglesia, pero si se trata del concepto general, usa mysterium o sacramentum indistintamente, de modo que aplica el mismo contenido a uno y otro. Si reducimos a esquema las diversas acepciones -prescindiendo de los sacramentos paganos- nos encontramos con cuatro significaciones del término: a) el sentido genérico de signo sin una clara relación causal ${ }^{138}$, al menos no explicitada ${ }^{139}$; b) los sacramentos del Antiguo Testamento, que no confieren ni contienen la gracia $^{140}$; c) los sacramentos del Nuevo Testamento, que contienen y confieren la gracia ${ }^{141} ;$ d) un último sentido, que incluye desde la generación eterna del

$35 \quad L G 1$.

136 Conf. M. J. Le Guillou, Le Christ et l'Eglise, p. 156-175, aunque su objetivo es distinto.

137 I Ad Cor, Prol. Conf. P. Garland, The definition of sacrament; P. Roszak, "Mysterium" en la teología.

138 La mera idea de signo sin causalidad aparece en la definición que da de sacramento en su obra In IV Sent. dist. 1, q. 1, a. 1: "Dicendum, quod sacramentum dicitur a sacrando active. Hoc autem potest fieri tripliciter. Aut efficiendo tantum, et sic res sacra dicitur sacramentum, ut dicit Magister, sicut Christi passio quae est causa meritoria sanctificationis nostrae. Aut signando tantum et sic definitur primo a Magistro: Sacramentum est sacrae rei signum. Aut utroque modo, et sic definitur ab Augustino secundum expositionem Magistri in littera propositam: Sacramentum est invissibilis gratiae visibilis forma, cuius similitudinem gerit et causa existit".

139 "Claudebatur ergo sub signaculo circuncissionis secretum incarnationis Chris ti ex semine Abrahae" (Ad Rom 4,11). A veces expresa la relación del sacramento del matrimonio con Cristo y la Iglesia, indicando la unión entre los dos (Suppl. q. 95, a. 1, sed c; I Ad Cor 7,2; III, q. 65, a. 3) o su unicidad (I Ad Tim. 3,2; Ad Tit. 1,6). Que la mujer nazca del varón es signo de que la Iglesia tiene su principio de Cristo (I, q. 92, a. 2).

140 Ad Gal 2,16.

141 Ad Gal 2,16. 
Verbo $^{142}$, hasta la salvación de los fieles ${ }^{143}$ y los misterios paganos ${ }^{144}$, es decir, toda la economía salvífica.

Comencemos por fijarnos en la cuarta acepción de esta palabra, que representa como el resumen de toda la economía y que el Santo incluye bajo dicho término de acuerdo con una tradición, que se remonta a los Padres.Hay un primer dato común: el ser algo oculto y que sólo Dios puede revelar. El Angélico razona esta afirmación en diversas ocasiones. En un texto se fija en la pequeñez del entendimiento humano para penetrar los misterios y llega a esta conclusión:"In mysterio, quae abscondita est; haec sapientia abscondita est ab hominibus, inquantum hominis intellectum excedit"145.Por otra parte, el misterio es obra de Dios solamente, y por tanto sólo Él puede tomar la decisión de realizarlo o no. La dispensación del misterio es obra exclusiva del amor de Dios, ya que únicamente depende de su voluntad el revelarlo ${ }^{146}$.

La Encarnación fue el momento cumbre de la revelación del sacramento, dato que no consiste en un hecho histórico transeúnte, sino que por él la $\mathrm{Hu}-$ manidad de Cristo se convierte en un perenne misterio, a través de la cual nos viene la gracia ${ }^{147}$. Por eso la naturaleza humana de Cristo es llamada mysterium, término que aplica también a su pasión, la cual junto con la encarnación es el camino para llegar a la gloria ${ }^{148}$. Si utiliza el término misterio para hablar de la Humanidad de Cristo, es natural que también lo atribuya a sus consecuencias: la salvación de los fieles ${ }^{149} \mathrm{y}$ de los paganos ${ }^{150}$; es más, a la salvación de todo el cosmos("restaurativum mundi") ${ }^{151}$, ya que hasta ahí llega la influencia de Cristo encarnado.Santo Tomás llama a la Humanidad de Cristo mysteriume instrumentum de la Divinidad, porque a través de ella nos vienen los dones salvíficos.

Si resumimos su pensamiento, reduciéndolo a las leyes que sirven de base del razonamiento al Angélico nos encontramos con una primera de corte antropológico: la visibilidad sacramental se acomoda al propio ser visible del hombre, de modo que su estructura tenga una cierta conformidad con él, y así

\footnotetext{
142 Ad Rom 1,3.

143 Ad Eph 3,8.

144 Ad Col 1,27. También encontramos el término "mysterium iniquitatis", tomado del propio San Pablo, con el sentido de maldad oculta y activa. Conf. II Ad Tess 2,7.

145 I Ad Cor 2,7.

146 Ad Eph 3,19.

147 Ad Rom 1,7.

148 STh II-II, q. 2, a. 7.

149 Ad Eph 3,8.

150 Ad Col 1,27; Ad Rom 16,25.

151 I Ad Ti 3,16.
} 
como el hombre se compone de cuerpo y alma, también el sacramento consta de "rebus visibilibus et verbis" ${ }^{52}$. Junto a esta ley e íntimamente ligada a ella, establece el Santo la ley cristológica: los sacramentos se han de asemejar a la causa universal de salvación, de donde les viene su poder salvífico ${ }^{153}$, y que no es otra sino Cristo ${ }^{154}$.

Eficiencia y semejanza son las dos notas, que establecen la conformación del sacramento al Verbo Encarnado. En cuanto a la semejanza -dice el Aquinatense- así como el sacramento consta de palabra y elemento sensible, en Cristo la carne se une al Verbo ${ }^{155}$. Pero esta semejanza no es estática, sino dinámica, de modo que la relación activa entre Verbo y carne corresponde de modo analógico a la interacción entre elemento y palabra ${ }^{156}$.La analogía entre sacramento y Verbo encarnado es tan clara, que con toda razón podemos llamar a Cristo -de acuerdo con el pensamiento de Santo Tomás- "Sacramento fontal o primordial" 157.

El paso de la aplicación del término sacramentum a la Iglesia es lógico, si partimos de su aplicación a la Humanidad de Cristo, pues también la Iglesia está constituida por un elemento interior y permanente -"coniunctio ad Deum" - y otro exterior, visible y transitorio. El Aquinatense aclara la relación entre Cristo y la Iglesia en la exégesis de Eph 5,32, al comparar esa relación con el matrimonio. Dice el Angélico: "Et haec quidem inseparabilitas matrimonii praecipue causatur inquantum est sacramentum coniunctionis indissolubilis Christi et Ecclesiae, vel Verbi et humanae naturae in persona Christi. Eph. 5,

152 "Secundo possunt considerari sacramenta ex parte hominis qui sanctificatur, qui componitur ex anima et corpore: cui proportionatur sacramentalis medicina, quae per rem visibilem corpus tangit, et per verbum ab anima creditur" (STh III, q. 60, a. 6).

153 "Congruum igitur fuit ut remedium quibus universalis causae virtus petingit ad homines, illius causae similitudinem haberent, ut scilicet in eis virtus divina invisibiliter operaretur sub visibilibus signis" (CG IV cap. 56).

154 "Sacramenta novae legis... ab ipso Christo effluunt et quandam similitudinem ipsius in se habent" (STh III, q. 60, a. 6, ad 3).

155 "Primo enim possunt considerari (sacramenta) ex parte causae sanctificantis, quae est Verbum Incarnatum: cui sacramentum quodammodo conformatur in hoc quod rei sensibili verbum adhibetur, sicut in mysterio incarnationis carni sensibili est Verbum Dei unitum" (STh III, q. 60 , a. 6; conf. In IV Sent. dist. 1, a. 3).

156 "Et sicut caro Christi sanctificata est, et virtutem sanctificandi habet per Verbum sibi unitum, ita et res sacramentorum sanctificantur, et vim sanctificandi habent per verba quae in his proferuntur" (De art. fidei et Eccl. Sacr.).

157 "La semejanza (entre Verbo Encarnado y sacramento) viene expresada en el concepto de 'conformación': la estructura sacramental es una copia de la estructura del Verbo encarnado. En esta perspectiva la 'ley de la encarnación' sigue siendo el principio y la norma de la economía sacramental” (R. Cuesta, "Antropología sacramental de la Encarnación, p. 304). 
32: Sacramentum hoc magnum est in Christo et Ecclesia..."158. En otro momento, comentando también las palabras paulinas "Nam quae sub viro est mulier, vivente vero, alligata est legi", le conduce a la afirmación de la indisolubilidad del matrimonio. Esta indisolubilidad "praecipue causatur" -y señalo esa palabra, porque no sólo indica como en otros textos una relación de signo, sino de auténtica causalidad- en cuanto que es sacramentum de la unión indisoluble de Cristo y la Iglesia, es decir, en cuanto representa spirituale sacramentum ${ }^{159}$, ya que en el texto de San Pablo, seguido por Santo Tomás, a lo que se llama sacramento por antonomasia -sacramentum hoc magnum- no es al matrimonio sino a la relación Cristo-Iglesia. Podemos concluir, por tanto, que la Iglesia -en cuanto unida a Cristo, sin lo cual es impensable- es el magnum sacramentum.

Afirma, por tanto, el Angélico que entre el Verbo y la naturaleza humana de Cristo, por una parte, y Cristo y la Iglesia, por otra, se puede establecer una correspondencia. ¿Cuál puede ser ésta? Para Santo Tomás la Humanidad de Cristo con relación al Verbo es el Sacramentum-Mysterium, como ya hemos visto, luego la Iglesia es el Sacramentum de Cristo, aunque en uno y otro caso esa noción se realiza de modo analógico. Esta analogía la indica -sin explicar-con el inciso in persona Christi, en cuanto que entre la Divinidad y la Humanidad de Cristo se da una unión personal y no así entre Cristo y la Iglesia ${ }^{160}$.

Como conclusión y resumen, podemos afirmar que la Iglesia es Sacramentum, indicando que no sólo es signo, sino causa de salvación. No podría ser de otro modo, ya que la Iglesia es un acontecimiento salvífico, y según la mentalidad de Santo Tomás, todos esos acontecimientos caen bajo la denominación genérica de sacramento.

\subsection{La Iglesia peregrina}

Hemos presentado la visión de la Iglesia tomasiana en cuanto comunión vital trinitaria. En ello consiste su naturaleza más intima, su misterio. Pero ¿cómo resuelve Santo Tomás la relación de esta realidad interior con el aspecto visible de la Iglesia peregrinante? Su afán por quedar en claro la sobrenaturalidad de la Iglesia ¿no habrá traicionado el elemento exterior? No olvidemos que se le ha

\section{Ad Rom 7,2.}

159 Suppl. q. 95, a. 1, sed c. 1.

160 Esta misma analogía la recoge el Concilio Vaticano II, citando a León XIII en Lumen Gentium n. 8: "Por eso, a causa de esta analogía nada despreciable, es semejante al del Verbo encarnado. En efecto, así como la naturaleza asumida está al servicio del Verbo divino como órgano vivo de salvación que le está indisolublemente unido, de la misma manera el organismo social de la Iglesia está al servicio del Espíritu de Cristo, que le da vida, para que el cuerpo crezca”. 
tachado de espiritualismo.P. Rodríguez conjuga la realidad visible e invisible de la Iglesia en santo Tomás con estas palabras:

Para santo Tomás la doctrina de la gracia no es doctrina de la mera interioridad, ni, mucho menos, espiritualismo. Es teología del don de Dios, tanto en sus manifestaciones invisibles como visibles. Por eso Tomás incluye en su doctrina de gratia Christi, no sólo la gracia gratum faciens, sino la estructura sacramental de la Iglesia, con su dimensión carismática, es decir, los sacramentos y sus ministros, como signos e instrumentos de la gracia, y los carismas o gracias gratis datae, que otorgan vocaciones, ministerios y funciones en la Iglesia [...]. En la Iglesia tanto la communio como el sacramentum -que la manifiesta y la causa- son, ambos, fruto de la gracia capital de Cristo, don del Espíritu Santo ${ }^{161}$.

El de Aquino no se limita a establecer el aspecto mistérico de la Iglesia, sino que estudia su concreción en los diversos estadios. La Iglesia de los resucitados no ofrece dificultad alguna, puesto que allí se realiza su naturaleza en plenitud y ha desaparecido el aspecto visible. Los resucitados -según expresión suyahan conseguido la edad perfecta y, por eso, a ese estadio lo llamará vera Ecclesia y ejemplar de la Iglesia peregrina. La Iglesia - una y única- se concreta en dos situaciones distintas, según que el metro que le sirve de norma -la comunión con Dios- se halle afincado en la eternidad o esté mediatizado por el tiempo.

Vamos a centrar nuestro estudio en el estadio peregrinante o Ecclesia militans. Despejemos antes una incógnita. La Iglesia, según Santo Tomas, comienza "desde los tiempos de Abel", y los fieles del Antiguo Testamento pertenecen a la misma Iglesia - "est eadem Ecclesia"-. Pero el santo establece una distinción neta entre los fieles del Antiguo Testamento, que pertenecen a la única Iglesia, y el Antiguo Testamento como institución, que es sólo sombra y figura, porque sus sacramenta son sólo protestationes fidei, dado que no conferían por sí la gracia y eran insuficientes para conducir al hombre hasta la unión con Dios. Sólo a la Iglesia del Nuevo Testamento puede, por tanto, calificársele como tal. Esta Iglesia -nos repetirá con insistencia- se constituye por la fe y el sacramento de la fe. La fe subraya la respuesta personal y comunitaria a la Palabra en su sentido mas amplio, mientras que el sacramento de la fe indica la raíz estructural eficaz y visible del ser peregrinante de la Iglesia.

La respuesta a la pregunta formulada fue resuelta en el apartado anterior, porque ya hemos adelantado un concepto que explica la relación entre lo visible e invisible: el concepto de sacramento.Este es el concepto-clave, recogido por la constitución Lumen gentium, que solventa la dificultad planteada. La sacramentalidad de la Humanidad de Cristo afecta a toda la realidad salvada 
y salvadora en la doble nota de visibilidad y eficacia, como transposición a nivel histórico de la realidad ontológica del compuesto teándrico. Pero no en el mismo grado, dada la esencial relación entre el Verbo y su Humanidad, que no se da entre Cristo y la Iglesia. Con estos presupuestos, podemos entender la intima relación entre la naturaleza de la Iglesia y su realización concreta histórica. Cierto que lo esencial y permanente en ella es la unión a Dios y en este sentido dirá el Angélico que "todo lo que no es gracia del Espíritu es accesorio, secundario y exterior". No obstante, para el santo teólogo la gracia y la unión a Dios-propias del tiempo presente- son de naturaleza encarnada, y por tanto habrá que distinguir en el estadio peregrinante el hecho de que la gracia sea visible, que es esencial supuesta la ley encarnativa, y el modo concreto de ser esa gracia en la escatología, donde ciertamente la visibilidad desaparecerá. Pero no debemos sin más concluir del hecho de la desaparición de la estructura sacramental que la gracia en el tiempo presente de la Iglesia sea espiritualizada por Santo Tomas. Aunque todo lo exterior sea secundario, desde cierto punto de vista de la encarnación, la Iglesia tiene necesariamente una estructura visible. Y es esta Iglesia y no otra -es la última aetas- el instrumento de la realización histórica de la verdadera caelestis Ecclesia transcendente. Resaltar el hecho del carácter definitivo y superior de la forma última de la Iglesia no es despreciar el estadio histórico ni espiritualizar la forma terrestre. En este estadio -sacramentos, ministerio sacerdotal etc.- son elementos esenciales y necesarios, que constituyen a la Iglesia como instrumento de salvación y por los cuales ella es constituida como una comunidad de salvados.

\section{Conclusión}

Estas pinceladas sobre la eclesiología del Angélico ponen de manifiesto su cercanía con la doctrina del Vaticano II. Sería un anacronismo pretender que Santo Tomas dijera la última palabra y que nada nuevo nos ofreciese el último concilio. Pero es el enfoque, lo radical, lo más hondo, aquello que une a Tomás y al Vaticano II: el aspecto comunional de la Iglesia, basado en la comunión trinitaria y el concepto de sacramento, como explicación de su visible eficacia. Hay un aspecto que pudiera parecer ausente del Aquinatense: el de la historicidad. Pienso que no es así, siempre que distingamos entre valor de la historia -en modo alguno ajeno a su pensamiento- y el historicismo que desconoce lo permanente.

Cuando elaboraba la tesis, en otra Universidad se gestaba un trabajo sobre la eclesiología de Calvino. Sorprendentemente las intuiciones primeras coincidían. Tal vez estos grandes maestros, estudiados en su pureza, puedan significar 
un acercamiento ecuménico. ¿No seguirá siendo Santo Tomas un interlocutor válido como lo fue en su tiempo en medio de corrientes tan diversas? Su entendimiento, verdaderamente libre como lo manifiesta su sana independencia teológica, sigue siendo modelo -así lo creo- para nuestra época.

Embarcados en una continua renovación eclesial, la figura y la doctrina eclesiológica de Tomas tiene -pienso- algo que decirnos. Él supo poner en claro lo esencial de la Iglesia -comunión vital con Dios- y sin embargo sabe dar a la estructura un lugar necesario en una comunidad peregrinante. La renovación del estudio de la eclesiología ha de ser transparencia de lo esencial, luz que manifieste a los ojos de los hombres lo más profundo de la realidad eclesial. En este sentido seguirá siendo válida su afirmación de que todo lo que no es gracia del Espíritu es "accesorio, secundario y exterior" y, por tanto, cambiante, mucho más si se trata de estructuras - montajes, diría alguno-, que impiden ver ese aspecto de comunión eclesial, que arrancando como gracia del Padre, nos envuelve por y en el Hijo mediante la acción del Espíritu. Es claro que, en el pensamiento de Santo Tomás, el sacramento eclesial, es decir, la estructura de la Iglesia, está al servicio de la comunión de la vida divina, que es su realidad última y profunda. Por eso debe reflejar la comunión interior y manifestarla como signo visible de esa communio. "Para Tomás, lo que de verdad es Iglesia proviene siempre de la gracia. No sólo -insisto- la communio profunda y escatológica, sino el sacramentum eclesial en su concreta figura histórica" ${ }^{162}$.

\section{Bibliografía}

Arias Reyero M., Thomas von Aquin als Exeget, Einsiedeln 1971.

Bandera, A., En la escuela de santo Tomás de Aquino: eclesiología histórico-salvifica, Barcelona 1996.

Benz, E., Joachim Studien III. Thomas von Aquin und Joachim von Fiore, Zeitschrift für Kirchengeschichte 53 (1934), pp. 52-116.

Bermejo, I., Santo Tomás y la Iglesia. A propósito de unos sermones de cuaresma (1273), Studium 46 (2006), pp. 269-319.

Biagi, R., La causalitá dell'umanitá di Cristo e dei Sacramenti nella "Summa Theologiae" di S. Tommaso d’Aquino, Edizioni Studio Domenicano, Bologna 1985.

Bonino, S.-T. (Coord), Thomistes o lactualité de Saint Thomas d'Aquin, Langres 2003. Bonino, S.-T., Saint Thomas au XX siècle, Saint Paul, Paris 1994.

Boüesse, H., La casualité efficiente instrumentale de l'Humanite de Christ et des sacrements chretiennes, RTh 39 (1934), pp. 370-393; 44 (1938), pp. 256-298.

Chenu, M.-D., Introduccion a l'etude de Saint Thomas d'Aquin, Paris 1954. 
Congar, J.-M.Y., Lidée de l'eglise chez s. Thomas d'Aquin, RSPT 24 (1940), pp. 31-38.

Congar, J.-M.Y., Traditio thomistica in materia ecclesiologica, Angelicum 43 (1966), p. 411.

Congar, J.-M.Y., L Église de Saint Augustin a l'époque moderne, Paris 1970.

Congar, Y., Vision de l'Eglise chez Thomas d'Aquin, Revue des Sciences Philosophiques et Théologiques 4 (1978), pp. 523-542.

Cuesta, R., Cristo, sacramento fontal según santo Tomás de Aquino, Escritos del Vedat 1 (1971), pp. 279-330.

Cuesta, R., Valor sacramental de la humanidad de Cristo como instrumento de la salvación según santo Tomás de Aquino, Escritos del Vedat 2 (1972), pp. 57-85.

Darquennes, A., La detinifion de l'Église d'aprés Saint Thomas d'Aquin, en: Lorganisation corporatitve du Moyen Age a la fin de l'Ancienne Regime, Louvain 1943.

De la Soujeole, B.-D., "Société" e "communion" chez saint Thomas d'Aquin, RTh 98 (1990), p. 587.

Elders, L., La Lectura super epistolam ad Hebraeos de Santo Tomás de Aquino, Scrip Theol 41 (2009), pp. 785-815.

Elders, L., The Lecturae of St. Thomas Aquinas of the Letters of the Apostle Paul to the Philippians and Colossians, DCom 13 (2009), pp. 131-149.

Elders, L., Tomás de Aquino, comentador de san Pablo, Scrip Theol 38 (2006), pp. 941 $-963$.

Fabro, C., La nozione metafisica di participazione secondo S. Tomasso d'Aquino, Torino 1950.

Geiselman, J., Christus und die Kirche nach Thomas von Aqin, Theol. Quart. 107 (1926), pp. 198-222; 108 (1927), pp. 233-255.

Grabmann, M., Die Lehre des heiligen Thomas von Aquin von der Kirche als Gotteswerk, Regensbourg 1903.

Hugon, E., La causalité instrumentale de l'Humanité de Jesus, RTh 13 (1905), pp. 44-48.

Jericó Bermejo, I., Anotaciones sobre la Iglesia en Santo Tomás de Aquino. A propósito de un libro llegado a España en 1982, La Ciudad de Dios 223 (2010), pp. 683-723.

Kaepelli, Th.M., Zur Lehre des hl. Thomas von Aquin von Corpus Christi Mysticum, Friburgo 1931.

Lafont, G., Estructuras y método en la Suma Teológica de S. Tomás, Madrid 1964.

Lavaud, M., Saint Thomas et la causalité efficiente instrumentale de la Sainte Humanité et des sacraments, RTh 32 (1927), pp. 292-316.

Le Guillou, M.J., Le Christ et l'Eglise. Théologie du mystère, Paris 1963.

Le Guillou, M.-J., Teología del misterio. Cristo y la Iglesia, Estela, Barcelona 1967.

Lécuyer, J., "La casualité efficiente des mystéres du Christ selon Saint Thomas", DCom 6 (1953) 91-120.

Malmberg, F., Ein Leib - ein Geist, Friburgo 1960.

Martínez, F., La Eucaristía y la unidad de la Iglesia en san Tomás de Aquino, Studium 9 (1969), pp. 377-404.

Martínez, M.A., La mediación de la humanidad de Cristo: clave de la lectura soteriológica de santo Tomás de Aquino, Ciencia Tomista 128 (2001), pp. 209-276, 417-439. 
Mersch, E., Le corps mystique du Christ. Études de théologie historique II, Paris 1951.

Mitterer, A., Geheimnisvoller Leib Christi nach St. Thomas Aquin nach Papst Pius XII, Viena 1950.

Ocáriz, F., Il mistero della Chiesa come Koinonia e la nozione metafísica di partecipazione, en: Veritatem in caritate. Studi in onore di Cornelio Fabro, Potenza 1991, pp. $158-161$.

Ponce, Cuéllar M., La naturaleza de la Iglesia según santo Tomás. Estudio del tema en el Comentario al "Corpus paulinum", Pamplona 1979.

Rantf, J., Die Stellung der Lehre von der Kirche in dogmatischen System, Aschaffenburg 1927.

Rodríguez, P., La comunión eclesial en la fe, DCom (2014), p. 195.

Rodríguez, P., La Iglesia como communio en la perspectiva de la gracia capital de Cristo, en: Atti del IX Congresso tomistico internazionale, Libreria Editrice Vaticana, Cittá del Vaticano 1991, pp. 296-303.

Roszak, P.P., Christus transformat se in Ecclesiam (In Ps. 21, n. 1). Eclesiología de Santo Tomás de Aquino, Scripta Theologica 42/1 (2010), pp. 31-55.

Roszak, P.P., "Mysterium" en la teología de santo Tomás de Aquino. Extracto de la Tesis Doctoral presentada en la Facultad de Teología de la Universidad de Navarra, Pamplona 2010.

Sabra, G., Thomas Aquinas' vision of the Church, Fundamentals of an ecumenical Ecclesiology, Mainz 1987.

Schmaus, M., Teologia dogmática, Tomo IV. La Iglesia, 2a ed., Madrid 1962.

Schmitz, R.M., De nexu Christum inter et Ecclesiam iuxta sanctum Thomam, DCom 43 (1990), pp. 271-287.

Ti-Ti Chen, J., La unidad de la Iglesia en el comentario de Santo Tomás a la Epístola a los Efesios, Scrip. Theol. 8 (1976), pp. 111-230.

Torrel, J.P., Iniciación a Tomás de Aquino, Pamplona 2002.

Torrell, J.-P., Saint Thomas d'Aquin, III Pars, Introduction, Revue de Jeunes t. II, Paris 2002.

Torrell, J.P., Yves Congar et l'ecclésiologie de saint Thomas d'Aquin, Revue des Sciences Philosophiques et Théologiques 2 (1998), pp. 201-242.

Vauthier, E., Le Saint-Esprit principe d'unité de l'Église d'aprés Saint Thomas d'Aquin, Corps Mystique et inhabitation du Saint-Esprit, MSR 5 (1948), p. 195.

Velasco, R., La Iglesia en la Tercera Parte de la Suma de Santo Tomás, Claretianum 10 (1970), pp. 109-138.

Villar, J.R., El Espíritu Santo, Principium unitatis Ecclesiae, Scripta Theológica 30 (1998), pp. 831-860. 